\title{
The role of phytoplankton dynamics in the seasonal and interannual variability of carbon in the subpolar North Atlantic - a modeling study
}

\author{
S. R. Signorini ${ }^{1,9}$, S. Häkkinen ${ }^{2}$, K. Gudmundsson ${ }^{3}$, A. Olsen ${ }^{4,5,}$, A. M. Omar ${ }^{4,5}$, J. Olafsson ${ }^{6}$, G. Reverdin $^{7}$, \\ S. A. Henson ${ }^{8}$, C. R. McClain ${ }^{9}$, and D. L. Worthen ${ }^{2,10}$ \\ ${ }^{1}$ Science Applications International Corp., Beltsville, Maryland, USA \\ ${ }^{2}$ NASA Goddard Space Flight Center, Cryospheric Sciences Branch, Greenbelt, Maryland, USA \\ ${ }^{3}$ Marine Research Institute, P.O. Box 1390, 121, Reykjavik, Iceland \\ ${ }^{4}$ Uni Bjerknes Centre, Allégaten 55, 5007 Bergen, Norway \\ ${ }^{5}$ Bjerknes Centre for Climate Research, Allégaten 55, 5007 Bergen, Norway \\ ${ }^{6}$ University of Iceland and Marine Research Institute, Reykjavik, Iceland \\ ${ }^{7}$ Laboratoire d'Océanographie Dynamique et de Climatologie, IPSL, Boîte 100, 4, Place Jussieu 75252, Paris \\ ${ }^{8}$ National Oceanography Centre, European Way, Southampton, SO14 3ZH, UK \\ ${ }^{9}$ NASA Goddard Space Flight Center, Ocean Ecology Branch, Greenbelt, Code 614.2, Maryland, USA \\ ${ }^{10}$ Wyle Information Systems Group, McLean, Virginia, USA \\ *now at: Institute of Marine Research, P.O. Box 1870 Nordnes, 5817 Bergen, Norway
}

Correspondence to: S. R. Signorini (sergio.signorini@ nasa.gov)

Received: 3 January 2011 - Published in Geosci. Model Dev. Discuss.: 3 February 2011

Revised: 22 March 2012 - Accepted: 29 March 2012 - Published: 15 May 2012

\begin{abstract}
We developed an ecosystem/biogeochemical model system, which includes multiple phytoplankton functional groups and carbon cycle dynamics, and applied it to investigate physical-biological interactions in Icelandic waters. Satellite and in situ data were used to evaluate the model. Surface seasonal cycle amplitudes and biases of key parameters (DIC, TA, $p \mathrm{CO}_{2}$, air-sea $\mathrm{CO}_{2}$ flux, and nutrients) are significantly improved when compared to surface observations by prescribing deep water values and trends, based on available data. The seasonality of the coccolithophore and "other phytoplankton" (diatoms and dinoflagellates) blooms is in general agreement with satellite ocean color products. Nutrient supply, biomass and calcite concentrations are modulated by light and mixed layer depth seasonal cycles. Diatoms are the most abundant phytoplankton, with a large bloom in early spring and a secondary bloom in fall. The diatom bloom is followed by blooms of dinoflagellates and coccolithophores. The effect of biological changes on the seasonal variability of the surface ocean $p \mathrm{CO}_{2}$ is nearly twice the temperature effect, in agreement with previous studies. The inclusion of multiple phytoplankton functional groups in the
\end{abstract}

model played a major role in the accurate representation of $\mathrm{CO}_{2}$ uptake by biology. For instance, at the peak of the bloom, the exclusion of coccolithophores causes an increase in alkalinity of up to $4 \mu \mathrm{mol} \mathrm{kg}{ }^{-1}$ with a corresponding increase in DIC of up to $16 \mu \mathrm{mol} \mathrm{kg}{ }^{-1}$. During the peak of the bloom in summer, the net effect of the absence of the coccolithophores bloom is an increase in $p \mathrm{CO}_{2}$ of more than $20 \mu$ atm and a reduction of atmospheric $\mathrm{CO}_{2}$ uptake of more than $6 \mathrm{mmol} \mathrm{m}^{-2} \mathrm{~d}^{-1}$. On average, the impact of coccolithophores is an increase of air-sea $\mathrm{CO}_{2}$ flux of about $27 \%$. Considering the areal extent of the bloom from satellite images within the Irminger and Icelandic Basins, this reduction translates into an annual mean of nearly 1500 tonnes $\mathrm{C} \mathrm{yr}^{-1}$.

\section{Introduction}

Coupled biogeochemical-physical numerical models together with observations are an essential tool to understand the interaction between physical and biological processes that create the observed temporal variability, on time scales 
ranging from days to years. Here, we developed a coupled biogeochemical-physical model system, which includes multiple phytoplankton functional groups and carbon cycle dynamics, and applied it to assess the role of phytoplankton dynamics in the seasonal and interannual variability of carbon in the subpolar North Atlantic. The rationale for the site selection relates to a combination of environmental and biological factors, e.g., large range in mixed layer depth (MLD), low mean horizontal advection, clear seasonal succession of phytoplankton species, and bloom intensity. Spring phytoplankton blooms in the surface water of the North Atlantic Ocean and adjacent seas are known to cause a precipitous reduction of surface water partial pressure of carbon dioxide $\left(p \mathrm{CO}_{2}\right)$ and the concentrations of $\mathrm{CO}_{2}$ and nutrients on a seasonal basis (Takahashi et al., 1993). In addition, research during the last decade has increased awareness of the relationship between key phytoplankton groups and their pivotal roles in the biogeochemical cycles of a range of elements (Boyd et al., 2010). For example, coccolithophores occupy a central role in the carbon cycle by the conversion of dissolved inorganic carbon (DIC) to both particulate organic carbon (POC) and particulate inorganic carbon (PIC) forms, albeit uncertainties exist over whether coccolithophore blooms are net sinks or sources of $\mathrm{CO}_{2}$ to the atmosphere (Boyd and Trull, 2007). The ratio of PIC to POC in exported biogenic matter determines the relative strength of the biological carbon pump and consequently the flux of $\mathrm{CO}_{2}$ across the surface ocean-atmosphere interface. Other functional groups, such as diatoms and dinoflagellates, are also important in the sequestration of carbon from the atmosphere to the deep ocean. The ability of some species of diatoms to form chains with built-in silica ballast and to produce large fast-sinking aggregates during the declining phase of the blooms means that they are key vectors in exporting and sequestering POC to the deep ocean (Lampitt, 1985). The competitive success of phytoplankton functional groups has important links to the environmental conditions. Although the predictive outcome of competition between two or more species has seldom been tested in the marine environment, some laboratory and mesocosm experiments reveal interesting results. Elaborate laboratory culture competition experiments with multiple marine phytoplankton species (coccolithophores excluded) (Sommer, 1994) and mesocosm experiments (Egge and Aksnes, 1992) show that diatoms dominate at high Si:N ratios, while diverse flagellates tend to dominate at low Si:N ratios. As Si is not regenerated above the MLD during a season, the growth period for diatoms fades out as the pycnoline is enforced and may be revoked every time a vertical mixing event occurs, as long as the available light is sufficient. Sommer (1994) showed no apparent effect of light intensities on the succession of functional groups, although it may exert some influence at the species level on the transition along the Si:N gradient. Nevertheless, light intensity has been shown to be very important on the blooms of certain species of coccolithophores. The large E. hux- leyi bloom south of Iceland in 1991 was modeled and high light was shown to be a positive cause (Tyrrell and Taylor, 1996). Under the intense bloom conditions, mixing was not very deep and therefore average light intensities in the surface layer were high.

The physical characteristics of the North Atlantic subpolar waters also have an impact on the biogeochemical and carbon cycle variability. The waters surrounding Iceland are characterized by the cold polar water of the East Greenland Current and Arctic water of the East Icelandic Current from the north, and the warm North Atlantic water of the Irminger Current from the south (Gudmundsson, 1998). Figure 1a shows a map of the subpolar North Atlantic and Nordic Seas and the mean location of the Arctic Front (AF). Sea ice is present throughout the year along the east coast of Greenland, with the ice edge extending farthest offshore in winter-spring, and retreating in the fall. Ice melt in summer-fall freshens (32$34 \mathrm{psu})$ the surface waters north of the AF. South of the AF waters are saltier $(\sim 35 \mathrm{psu})$ and warmer $\left(8\right.$ to $\left.12^{\circ} \mathrm{C}\right)$, as a result of Atlantic water intrusions. These hydrographic characteristics have an impact on the seasonal vertical mixing, as shown in model simulations. During winter and spring, MLDs average 100 to $500 \mathrm{~m}$ south of the AF, with deeper values in the Irminger and Icelandic Basins; in summer, the vertical stratification is significant, with MLDs less than $20 \mathrm{~m}$ (de Boyer Montégut et al., 2004; de Boisséson et al., 2010; Carton et al., 2008). North of the AF, the MLDs are shallow $(<40 \mathrm{~m})$ throughout the year due to the southward advection of fresher polar and Arctic waters, and ice melting during summer-fall. Some accounts of winter deep mixing are available for the region based on regular XBT surveys and CTD casts (G. Reverdin, personal communication, 2012). MLDs as deep as $500 \mathrm{~m}$ were found in the Irminger Current, in particular west of the Reykjanes Ridge, and occasionally close to Greenland and southwest of Iceland. In the central Irminger Sea, MLDs are not as deep, mostly ranging from 100 to $150 \mathrm{~m}$. However, there are indications from Argos floats that deep convective chimneys occasionally occur in the central Irminger Sea (as in early 2008) down to nearly $1000 \mathrm{~m}$ (Vage et al., 2009). These large seasonal changes in stratification and vertical mixing play an important role in the euphotic zone nutrient renewal and on the onset and duration of the phytoplankton spring bloom (Henson et al., 2006). Variability in the intensity of primary production in general and of the timing of spring bloom in particular (Henson et al., 2009) affects the population dynamics of higher trophic levels, such as the commercially important Atlanto-Scandian herring (Jakobsson, 1978) in the region. The annual phytoplankton carbon production in the waters around Iceland is quite high. According to a recent estimate (Zhai et al., 2012), based on available regional measurements on the photosynthetic capacity and satellite biomass data, the annual primary production is $179 \pm 36$ and $238 \pm 22 \mathrm{gC} \mathrm{m}^{-2} \mathrm{y}^{-1}$ for the Arctic and the Atlantic waters, respectively. In addition, seasonal and interannual changes in phytoplankton production 


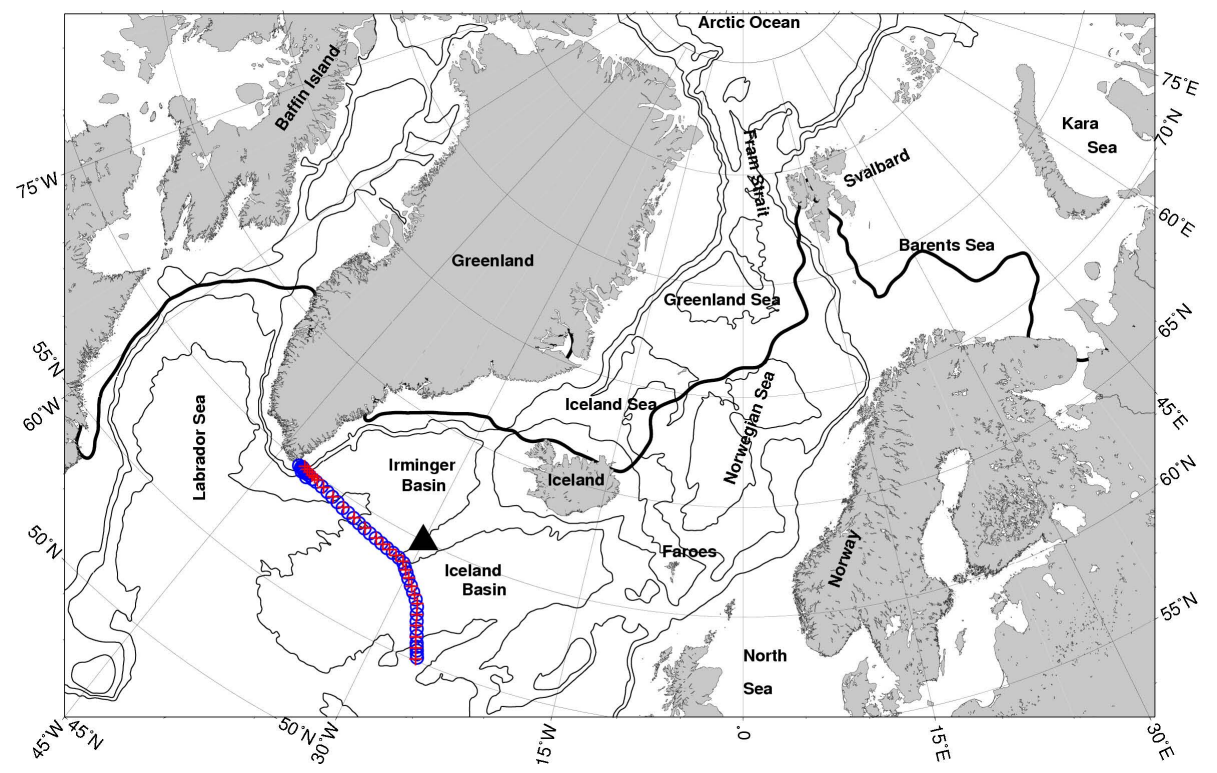

Fig. 1a. Map of subpolar North Atlantic and Nordic Seas. The black thick line is the Arctic Front represented by the $4{ }^{\circ} \mathrm{C}$ isotherm (from GPOMZ 1948-2009 climatology) and the thinner lines are the bathymetry contours (500, 1500, and $3000 \mathrm{~m})$. The black triangle indicates the site chosen for the 1-D ecosystem-carbon model. The blue circles (1994) and red crosses (2004) indicate the location of the two repeat CARINA transects.

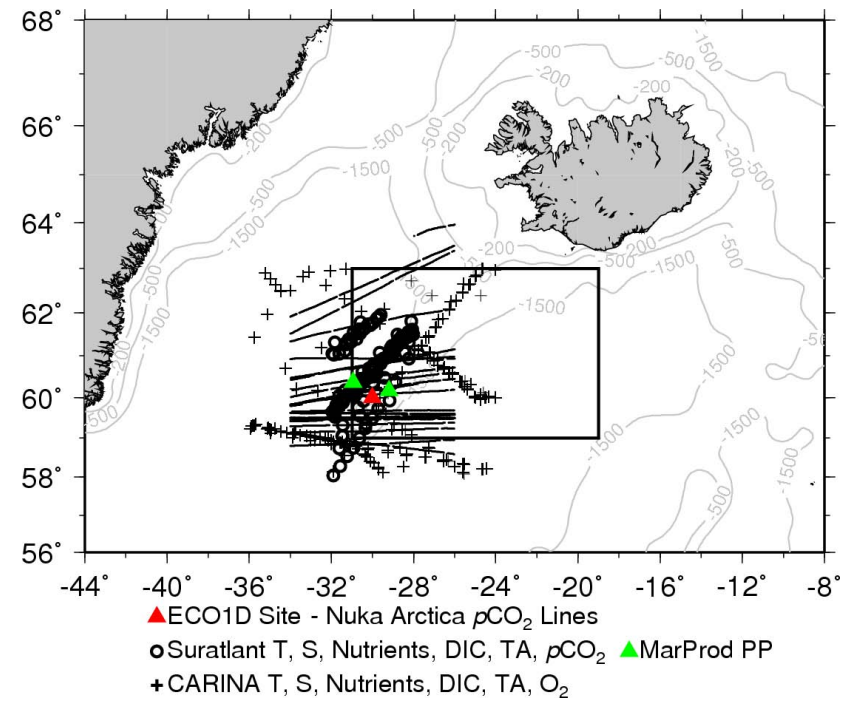

Fig. 1b. Map showing the spatial distribution of in situ PP, nutrients, and carbon data used for model evaluation. The rectangular box bounds the CPR standard area B6, from which taxonomy data were obtained for evaluation.

are tightly coupled to atmospheric $\mathrm{CO}_{2}$ uptake and surface ocean $p \mathrm{CO}_{2}$ variability (Corbiere et al., 2007), and therefore a major component of the carbon cycle.

\section{Model description}

\subsection{Ice-ocean model (GPOMZ)}

Physical forcing for the 1-D ecosystem/carbon model, ECO1D-2.0(location shown by the black triangle in Fig. 1a at $30^{\circ} \mathrm{W}$ and $60^{\circ} \mathrm{N}$ ), is provided by a three-dimensional (3D) coupled ice-ocean model of the Arctic and North Atlantic (Mellor et al., 2002). The sigma-coordinate version has been previously used to simulate North Atlantic and Arctic variability (Hakkinen, 1999, 2001; Hakkinen and Geiger 2000). Monthly temperature and salinity profiles obtained from GPOMZ are interpolated to the time steps and depths required by ECO1D-2.0. These profiles are assimilated at each time step by the 1-D model. A detailed description of GPOMZ is provided in Appendix A. In this subsection we present a few GPOMZ products to describe some of the physical properties of the region. In Appendix A we show three figures with physical properties derived from GPOMZ. Figure A1 shows the annual SST composites for 2009, derived from GPOMZ and MODIS-Aqua; Fig. A2 shows a comparison between GPOMZ and MODIS SST at ECO1D-2.0 simulation site, and Fig. A3 shows a comparison between the seasonal MLD from de Boyer Montégut et al. (2004) and GPOMZ at the ECO1D-2.0 site. Although there is a reasonable agreement between model and MODIS SST fields in Fig. A1, the Arctic Front is further away from the study site compared to MODIS data. However, as it will be shown later in section 4 and Appendix A, this has little or no effect on our results, since the bias-corrected SST at the modeling 

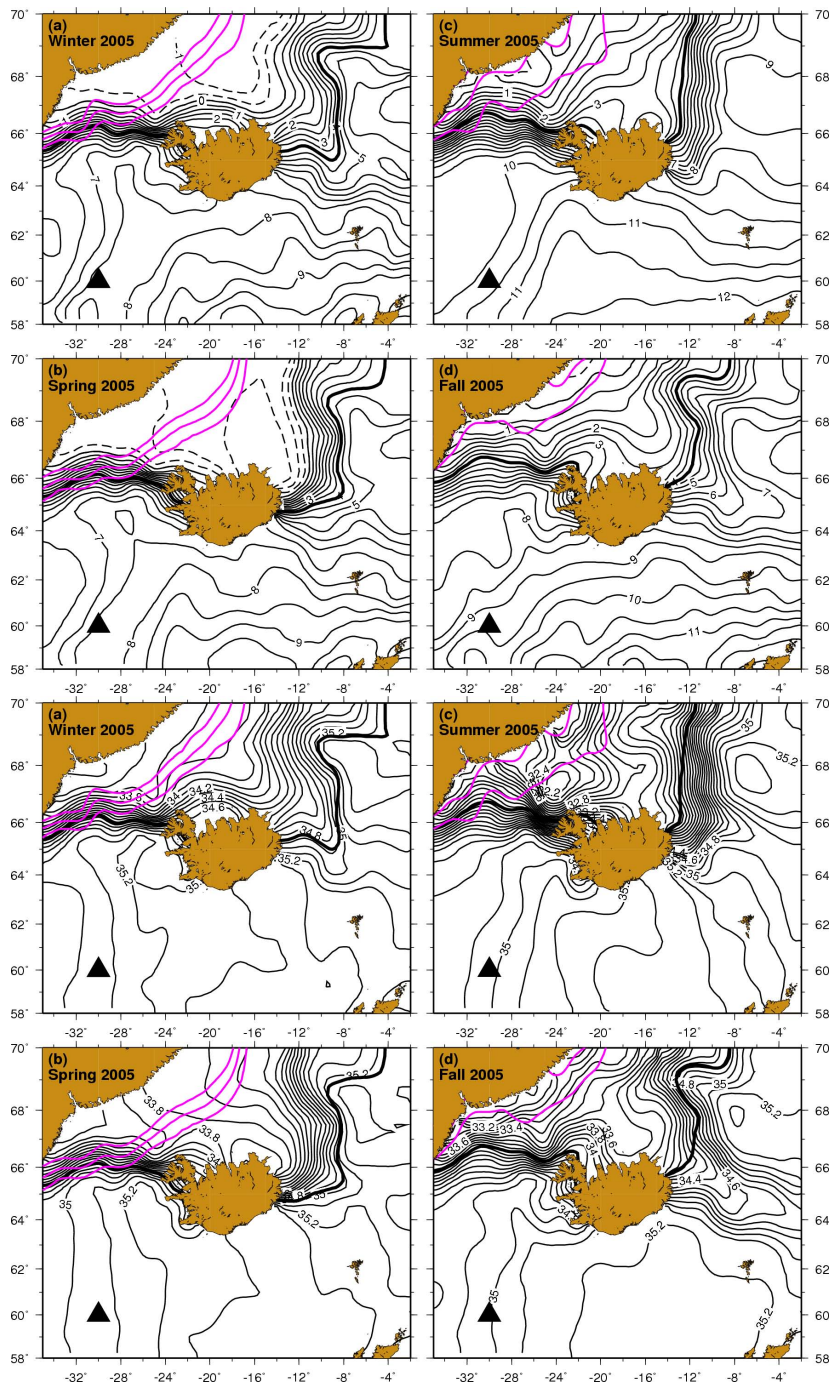

Fig. 2. Seasonal maps of GPOMZ SST (left panel, a through d) and SSS (right panel, a through d) for 2005. The 3D ice concentration contours $(20 \%, 40 \%$, and $60 \%$ purple contours) derived from monthly NOAA/ESRL/PSD optimally interpolated data (OI) are superposed. The ECO1D-2.0 site is shown by the black triangle and the thick black lines indicate the Arctic Front.

site agrees well with the data. The bias correction was done based on WOA05 monthly climatology and the resulting SST time series at the ECO1D-2.0 site was validated based on in situ observations and MODIS data (see caption in Fig. A2 for explanation).

Figure $1 \mathrm{~b}$ shows a smaller-scale map containing the locations of the in situ data available for model evaluation. The 1-D model location lies on the western edge of the Reykjanes Ridge and within the Irminger Current, in an area where winter mixing is extremely vigorous (mixed layer depths approaching $600 \mathrm{~m}$ ) (Bailey et al., 2005) and springsummer phytoplankton blooms are substantial (Fernandez et al., 1993; Holligan et al., 1993b; Weeks et al., 1993). The convergence of the polar and North Atlantic water masses form the Arctic Front, which varies slightly in location seasonally (Fig. 2) and is identified by strong gradients of sea surface temperature (SST) and salinity (SSS). The AF runs east-west, approximately along $66^{\circ} \mathrm{N}$ to the west of Iceland, and north-south between $12^{\circ} \mathrm{W}-8^{\circ} \mathrm{W}$, and then further in northerly direction from approximately $69^{\circ} \mathrm{N}$, northeast of Iceland. The above features are clearly shown in Fig. 2, which shows the seasonal SST and SSS fields for $2005 \mathrm{ob}-$ tained from GPOMZ (Mellor et al., 2002). GPOMZ products are available at monthly intervals for 1948-2009. We chose to show fields for 2005 as an example because it coincides with the year during which most of the surface ocean $p \mathrm{CO}_{2}$ data are available (Chierici et al., 2009; Olsen et al., 2008).

The climatologic (1954-2008) seasonal surface currents from GPOMZ are shown in Fig. 3. Although there may be some differences between the model currents and what is known of the regional circulation patterns (Poulain et al., 1996; Gudmundsson, 1998), Fig. 3 shows a general cyclonic circulation in the Irminger Sea north of $59^{\circ} \mathrm{N}$, and a convergence south of the Denmark Strait between the cyclonic circulation and the East Greenland Current, in agreement with observations.

\subsection{Ecosystem-carbon model (ECO1D-2.0)}

The mixed layer component of ECO1D-2.0 originates from an existing one-dimensional physical-biogeochemical model (Signorini et al., 2001a; Signorini et al., 2001b), which utilizes a turbulence closure mixed layer scheme (Mellor and Yamada, 1982), identical to the scheme used for GPOMZ. ECO1D-2.0 has a vertical coordinate system that provides parameter values, including horizontal velocity components, temperature, salinity, and the vertical diffusivity coefficient, $k_{v}$, at each time step and grid point. The surface boundary layer is resolved more accurately by using a stretched vertical coordinate with higher resolution near the surface.

The biogeochemical component of ECO1D-2.0 derives from a previous ecosystem model, ECO1D-1.0, configured for and applied at the Bermuda Atlantic Time Series (BATS) site, described in Signorini et al. (2003). ECO1D-2.0 includes additional conservation equations for diatoms, coccolithophores, calcium carbonate $\left(\mathrm{CaCO}_{3}\right)$, silicate $\left(\mathrm{SiO}_{2}\right)$ and alkalinity. Figure 4 shows a diagram illustrating the model components and their couplings. The details of the ecosystem model are described in Appendix B.

Figure 5 (to be discussed later in Sect. 4) shows the satellite-derived net primary production (NPP) and calcification rate $\left(P_{\mathrm{PCaCO} 3}\right)$ for June 1998, during which the strongest coccolithophore bloom occurred during the SeaWiFS mission (Raitsos et al., 2006), with the location of the modeling site (black triangle at $30^{\circ} \mathrm{W}$ and $60^{\circ} \mathrm{N}$ ). NPP was obtained from monthly $\mathrm{CbPM}$ files and the $P_{\mathrm{PCaCO}}$ monthly composite was computed using the algorithm of Balch et al. (2007). The site lies at the western edge of the Reykjanes 

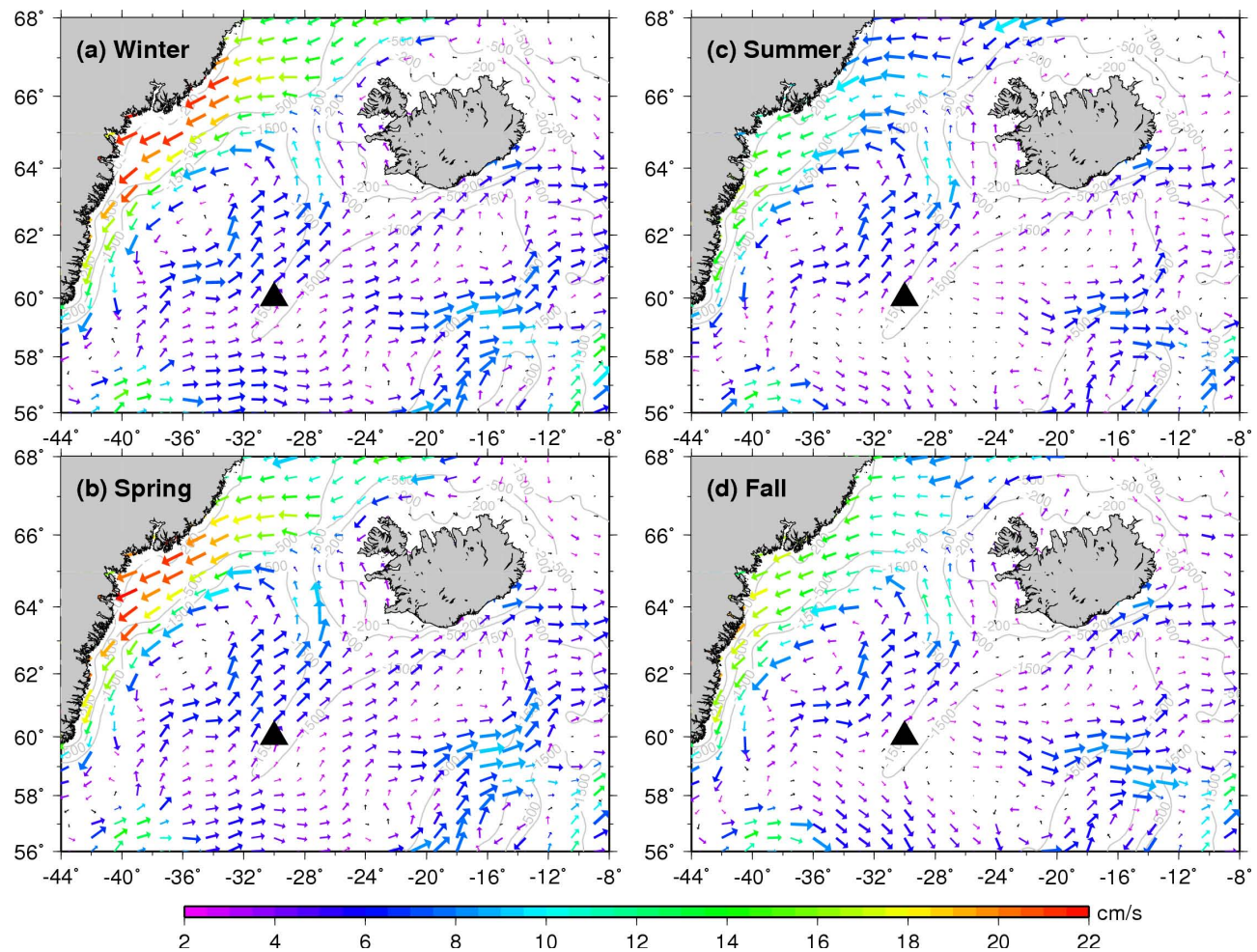

Fig. 3. Map showing the 3-D model seasonal climatologic (1955-2008) surface currents and the location of the 1-D ecosystem model simulations (black triangle).

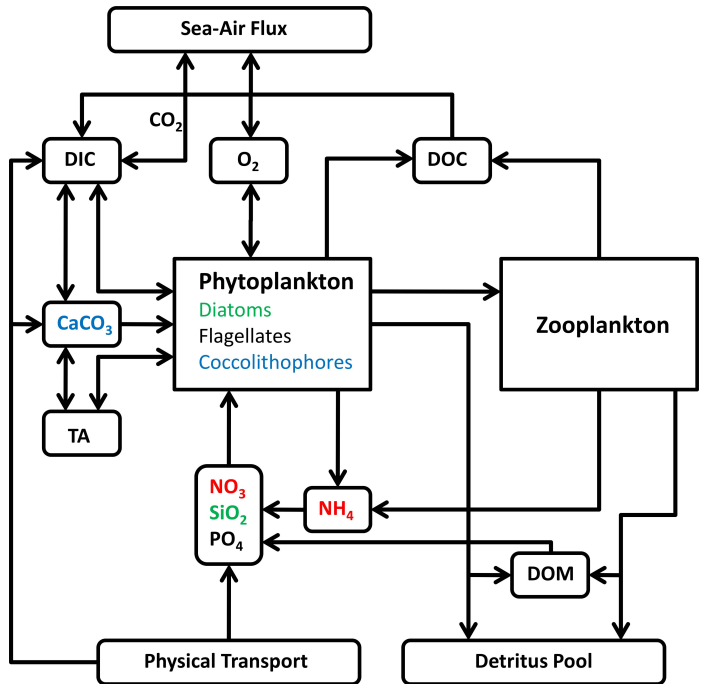

Fig. 4. Diagram of main components of the one-dimensional biogeochemical model. The color code for some of the variables indicates unique association of processes, e.g., ammonium nitrification, uptake of silica by diatoms only, and calcification by coccolithophores.

Ridge in the Irminger Sea, a region of high phytoplankton productivity. The local depth is $\sim 1500 \mathrm{~m}$, but the model vertical grid extends to $1000 \mathrm{~m}$ only, which accommodates the deepest MLD. ECO1D-2.0 can be forced by winds and other relevant atmospheric parameters to calculate heat and freshwater fluxes originating from NCEP-II Reanalysis products, which determined the 28-yr period of simulation (19812008). As an option, surface temperature and salinity can be specified at the surface instead of heat and freshwater fluxes. The physical component of ECO1D-2.0 is configured on a vertically-stretched logarithmic grid, while the biogeochemical component uses a uniform vertical grid with $1 \mathrm{~m}$ resolution. Deep water $(z>200 \mathrm{~m})$ nutrient values are nudged within the bounds of the observed monthly climatology from the World Ocean Atlas 2005 (see details in Appendix B), and temperature and salinity values at all depths are nudged to values derived from the GPOMZ using the Newtonian relaxation method (see Appendix B for details). The Newtonian relaxation method (nudging) is a simple form of data assimilation. Surface salinity (SSS) from GPOMZ is imposed at the top layer of the 1-D model, which accounts for all processes that alter SSS, including ice melting-freezing and precipitation-evaporation. The Reynolds and Smith optimally interpolated (RSOI) SST is imposed at the model surface instead of heat flux.

Deep water dissolved inorganic carbon (DIC) is nudged (relaxation time of 2 days) to values obtained from a dataderived equation (DIC vs. $T$ ) and model temperature at each time step $(0.5 \mathrm{~h})$, plus has a superimposed DIC decadal trend 

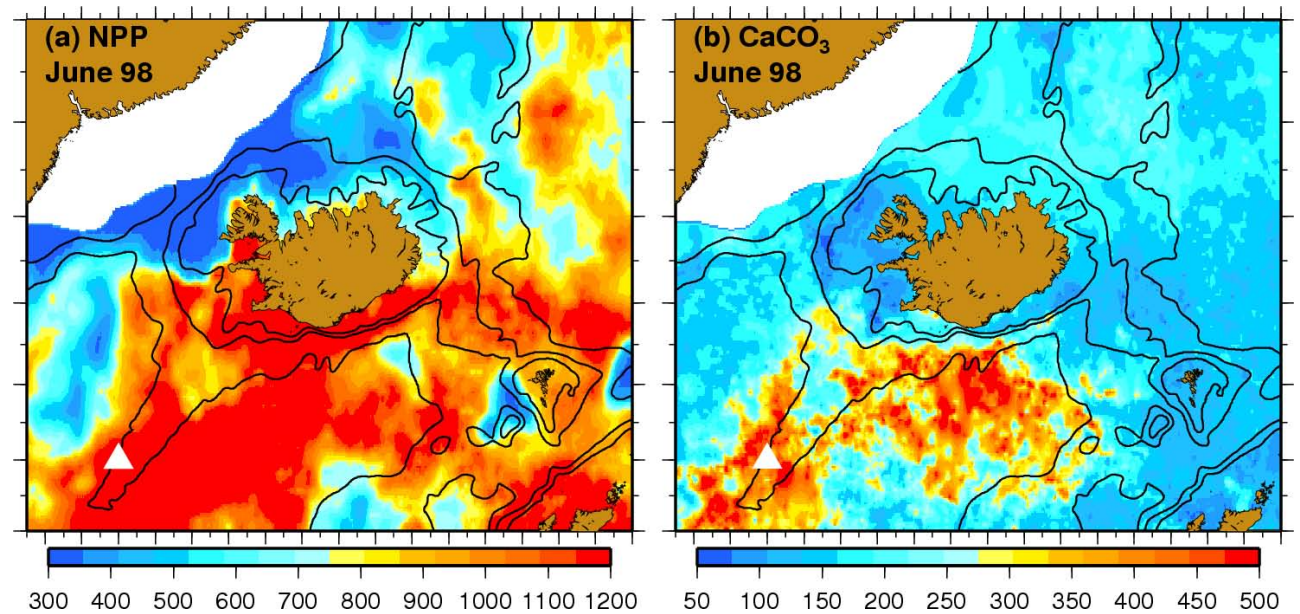

Fig. 5. Satellite-derived net primary production (a) and calcification rate (b) for June 1998 (units in $\mathrm{mg} \mathrm{C} \mathrm{m}^{-2} \mathrm{~d}^{-1}$ ). The white triangle indicates the position of the 1-D ecosystem-carbon model simulations. Ice concentrations greater than $10 \%$ are masked in white.

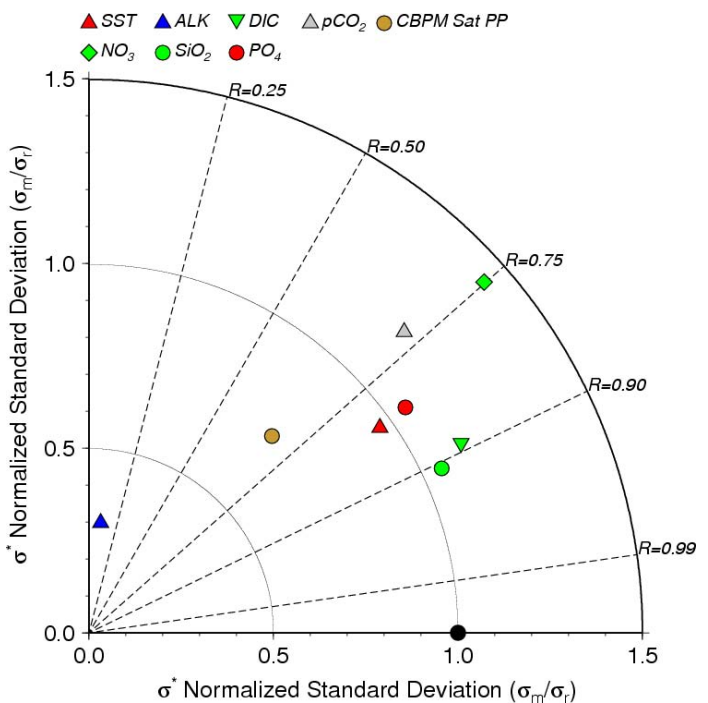

Fig. 6. Taylor diagram showing normalized standard deviations $\left(\sigma^{*}\right)$ and correlation coefficients $(R)$ for model versus reference values, consisting of all measured variables from different available sources. All comparisons were done using surface values, except for PP which is a vertically integrated value. The black circle shows the result that would be obtained for a perfect fit between model and data, e.g., identical standard deviations and $R=1$.

consistent with observations . The total alkalinity (TA) is nudged in deep water to values also obtained from a dataderived equation (TA vs. T and $\mathrm{S}$ ), with a relaxation time scale of 10 days. The DIC and TA equations are based on CARINA observations, with details described in the Appendix B.

The adopted method of forcing the one-dimensional biogeochemical model (ECO1D-2.0) with physical fields from GPOMZ relies on the assumption that vertical mixing pro- cesses, e.g., convective overturning and wind mixing, play a much more important role in the biological variability than the lateral advective processes. To better quantify and justify this assumption, an assessment of the nitrate transport via vertical mixing and horizontal advection was performed using a combination of monthly climatologic nitrate profiles from WOA05 and monthly climatologic (19812008) physical parameters (eddy vertical diffusivity, $k_{v}$, and north and east velocity components, $u$ and $v$ ) from GPOMZ. The calculation was done within $\pm 2^{\circ}$ of the modeling site at $60^{\circ} \mathrm{N}$ and $30^{\circ} \mathrm{W}$, and within the depth interval from 100 to $500 \mathrm{~m}$, in the upper part of the water column. The minimum depth of $100 \mathrm{~m}$ was chosen to avoid the euphotic depth, within which nitrate is consumed by phytoplankton, while the maximum depth of $500 \mathrm{~m}$ is dictated by the availability of monthly WOA05 nitrate. Spatial and temporal averages were done to the resulting horizontal divergence and vertical mixing components of the nitrate transport, $u \partial \mathrm{NO}_{3} / \partial x+v \partial \mathrm{NO}_{3} / d y$ and $\partial / \partial z\left(k_{v} \partial \mathrm{NO}_{3} / \partial z\right)$, respectively. The results demonstrate that our assumption is a valid one. The annual mean local horizontal divergence is $0.005 \mathrm{mmol} \mathrm{m}^{-3} \mathrm{~d}^{-1}$, while the vertical eddy diffusivity transport is $2.628 \mathrm{mmol} \mathrm{m}^{-3} \mathrm{~d}^{-1}$, a factor of $\sim 550$ times larger than the local horizontal divergence. The values for summer-fall (January-March and October-December) and spring-summer (April-September) are 0.007 and $0.003 \mathrm{mmol} \mathrm{m}^{-3} \mathrm{~d}^{-1}$ for horizontal divergence, and 5.124 and $0.133 \mathrm{mmol} \mathrm{m}^{-3} \mathrm{~d}^{-1}$ for vertical diffusion, respectively. Although the vertical diffusion of nitrate is significantly reduced in spring-summer, it is still $\sim 52$ times larger than the horizontal divergence. 

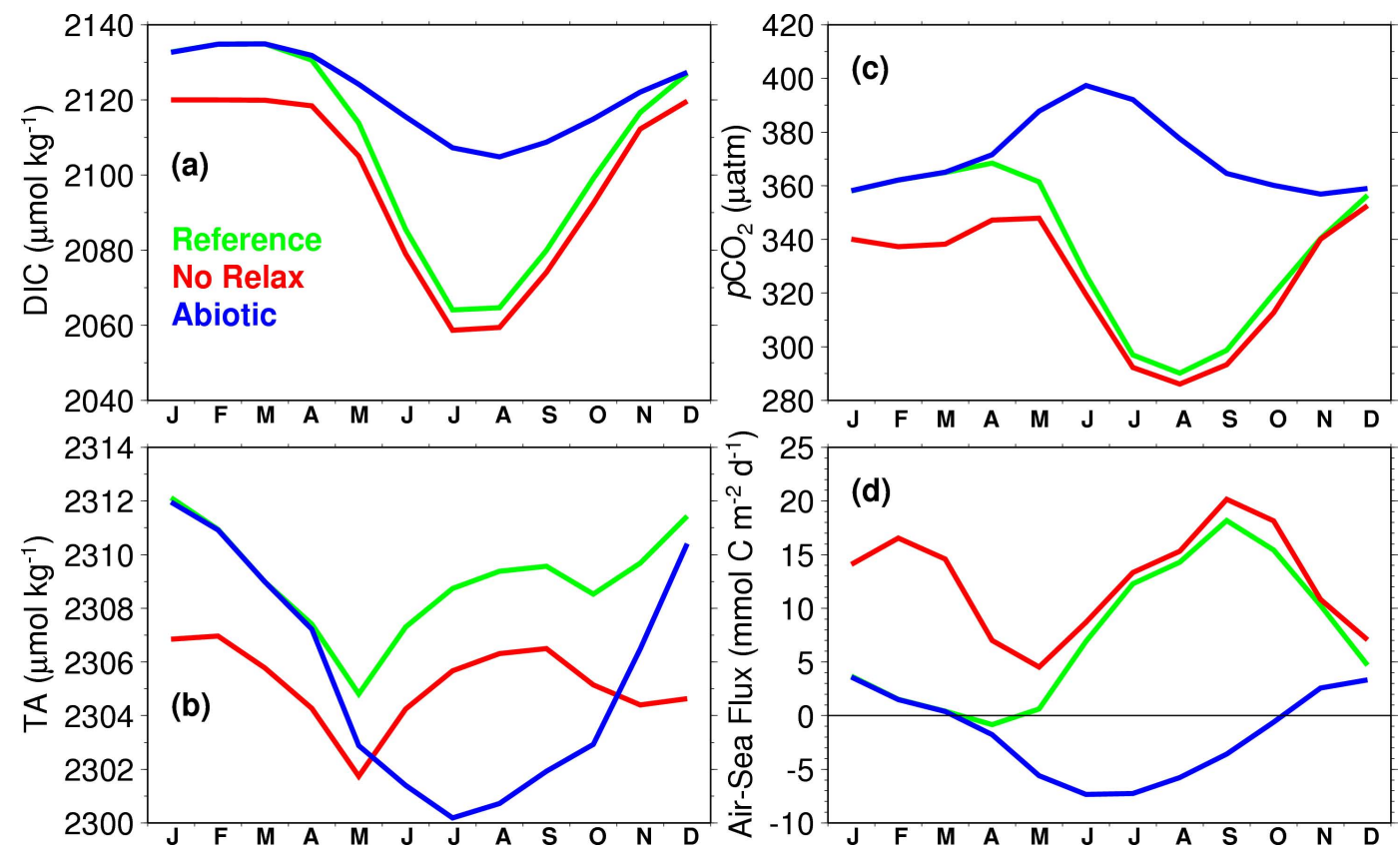

Fig. 7a. Climatologic seasonal variability of surface ocean DIC (a), TA (b), $p \mathrm{CO}_{2}$, and air-sea $\mathrm{CO}_{2}$ flux for three different model runs: reference (Experiment A, green), no DIC and TA relaxation and without bottom DIC trend (Experiment B, red), and abiotic ocean (Experiment C, blue).

\section{Satellite and in situ data sets}

We rely on a combination of satellite data and field observations to provide an evaluation framework for the model. The satellite-derived data sets consist of SeaWiFS Chl $a$, Reynolds and Smith optimally interpolated (RSOI) SST (Reynolds and Smith, 1995) and sea ice concentration. These data were obtained from NOAA_OI_SST_V2 data provided by the NOAA/OAR/ESRL PSD, Boulder, Colorado, USA, from their web site at http://www.esrl.noaa.gov/psd/. We use primary production from the carbon-based productivity model (CbPM, (Behrenfeld et al., 2005)). The satellitederived PP data were obtained from the ocean productivity web site at Oregon State University (http://www.science. oregonstate.edu/ocean.productivity/). The inputs for CbPM are Chl $a$ and backscatter at $443 \mathrm{~nm}$,estimated using the Garver-Siegel-Maritorena (GSM) semi-analytical algorithm (Maritorena et al., 2002) and monthly SeaWiFS water leaving radiances, SeaWiFS cloud-corrected PAR data, SeaWiFS mixed layer light attenuation coefficients at $490 \mathrm{~nm}$, advanced very high resolution (AVHRR) SST, and monthly mean regional mixed layer depths from the Fleet Numeric Meteorology and Oceanography Center (FNMOC) (Monterey, California). In addition, a limited amount of in situ PP data was obtained from $\mathrm{C}-14$ incubations conducted during early August 2002 on a Marine Productivity (MarProd) cruise sponsored by the Natural Environment Research Council (UK) onboard the RRS Discovery. Taxonomic data (cell counts) were obtained from the Continuous Plankton
Recorder (CPR) database (standard area B6 south of Iceland, http://www.sahfos.ac.uk/data-archive/standard-areas.aspx).

Surface ocean $p \mathrm{CO}_{2}$ data for 2005 were acquired from onboard the container ship $M / V$ Nuka Arctica (Chierici et al., 2009; Olsen et al., 2008). In addition, we used DIC, alkalinity, surface ocean $p \mathrm{CO}_{2}$, and nutrient in situ data from SURATLANTE (Corbiere et al., 2007; Metzl et al., 2010), and data from the CARbon IN the Atlantic Ocean (CARINA) Data Synthesis Project (Key et al. (2010); http://www. earth-syst-sci-data.net/2/105/2010/essd-2-105-2010.pdf).

The locations of all in situ data used to validate the 1-D ecosystem model are shown in Figure 1b. The atmospheric $p \mathrm{CO}_{2}$ required to obtain the $\mathrm{CO}_{2}$ flux at the atmosphereocean interface was obtained from GLOBALVIEW- $\mathrm{CO}_{2}$ (NOAA, ftp.cmdl.noaa.gov). Note that these data sets used for model validation are from the surface or near-surface, which are not part of the deep water data utilized for model forcing and boundary conditions.

\section{Ecosystem-carbon model evaluation}

Using the data sets shown in Fig. $1 \mathrm{~b}$ and discussed in Sect. 3, model versus data comparisons were compiled and analyzed. Due to the nature of the spatial distribution of the in situ data surrounding the model location, it is expected that some of the mismatches between model and observations are inherently related to the spatial variability and patchiness of measured quantities. For instance, the patchiness of primary 


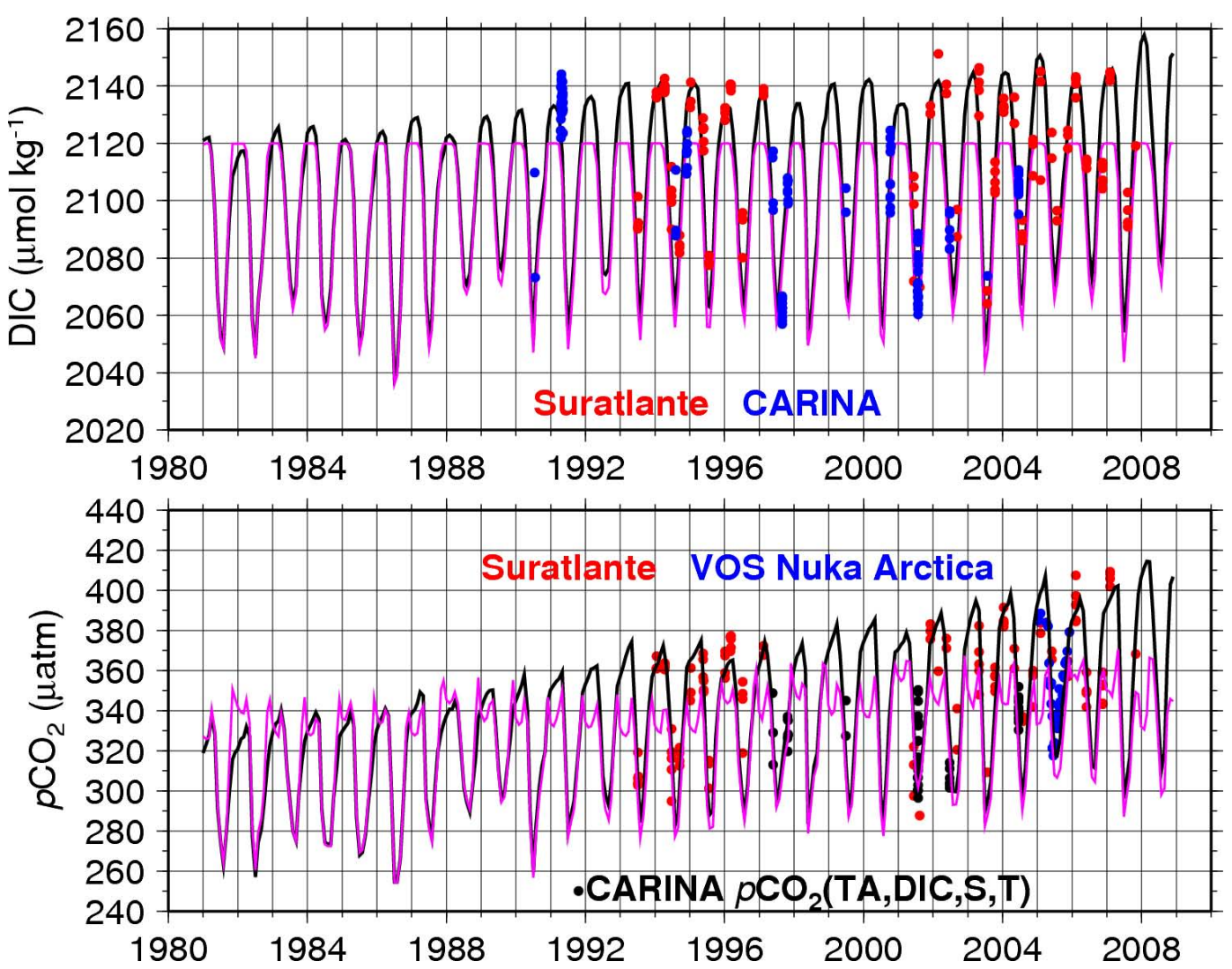

Fig. 7b. Time series of surface DIC (top) and ocean $p \mathrm{CO}_{2}$ (bottom) from two model experiments, one including deep water DIC and TA relaxation and bottom DIC trend (Experiment A, black lines) and one without it (Experiment B, purple lines). The red, blue and black circles represent the available data for comparison.

production and calcite production can be readily seen in the satellite maps shown in Fig. 5. However, in spite of this spatial mismatch between the model single point simulation and available measurements in multiple locations around the model site, with few exceptions, the overall agreement between model and observations is quite good. It will be shown later in this section that the majority of model versus observed parameters are statistically correlated with $p$-values well below 0.05 .

A quantitative approach based on metrics, assessment indices and skill scores is provided to evaluate model performance. For this purpose, we use a Taylor diagram (Jolliff et al., 2009) to conduct the model evaluation based on all available in situ and satellite observations. The normalized standard deviation $\left(\sigma^{*}\right)$ and the correlation coefficient $(R)$ from the model $(m)$ to reference field $(r)$ comparisons may be displayed on a single Taylor diagram (Fig. 6). Note that $\sigma^{*}$ is displayed in both $x$ and $y$ coordinates of the polar diagram of Fig. 6. The Taylor diagram is a polar coordinate diagram that assigns the angular position to the inverse cosine of $R$ $\left(\cos ^{-1}(R)\right)$. A correlation of zero is thus $90^{\circ}$ away from a correlation of 1 . The radial (along-axis) distance from the origin is assigned to the normalized standard deviation. The reference field point (black circle in Fig. 6), which is comprised of the statistics generated from a redundant reference to reference comparison, is indicated for the polar coordinate $(1.0,0.0)$. The model to reference comparison points may then be gauged by how close they fall to the reference point. This distance is proportional to the normalized unbiased root-mean-square difference, as defined by the equation RMSD $^{*}=\left(1.0+\sigma^{* 2}-2 \sigma^{*} R\right)^{0.5}$, where $\sigma^{*}=\sigma_{m} / \sigma_{r}$.

Inspection of Fig. 6 reveals that the great majority of model versus reference comparisons fall within significant $R$ values (0.7-0.9) and $\sigma^{*}$ close to 1 . Except for alkalinity (TA), all other $R$-values are significant at the $95 \%$ confidence level, with $p$-values well below 0.05 . The TA reference data have a relatively low correlation with the model, probably as a result of the low local TA variability, even though the bias between model and observations is small. The Taylor diagram does not provide an estimate for the bias, but Table 2 provides surface ocean means and standard deviations (STDs) for all the variables shown in the Taylor diagram. The means and STDs for the model variables are very close to the observed values. 

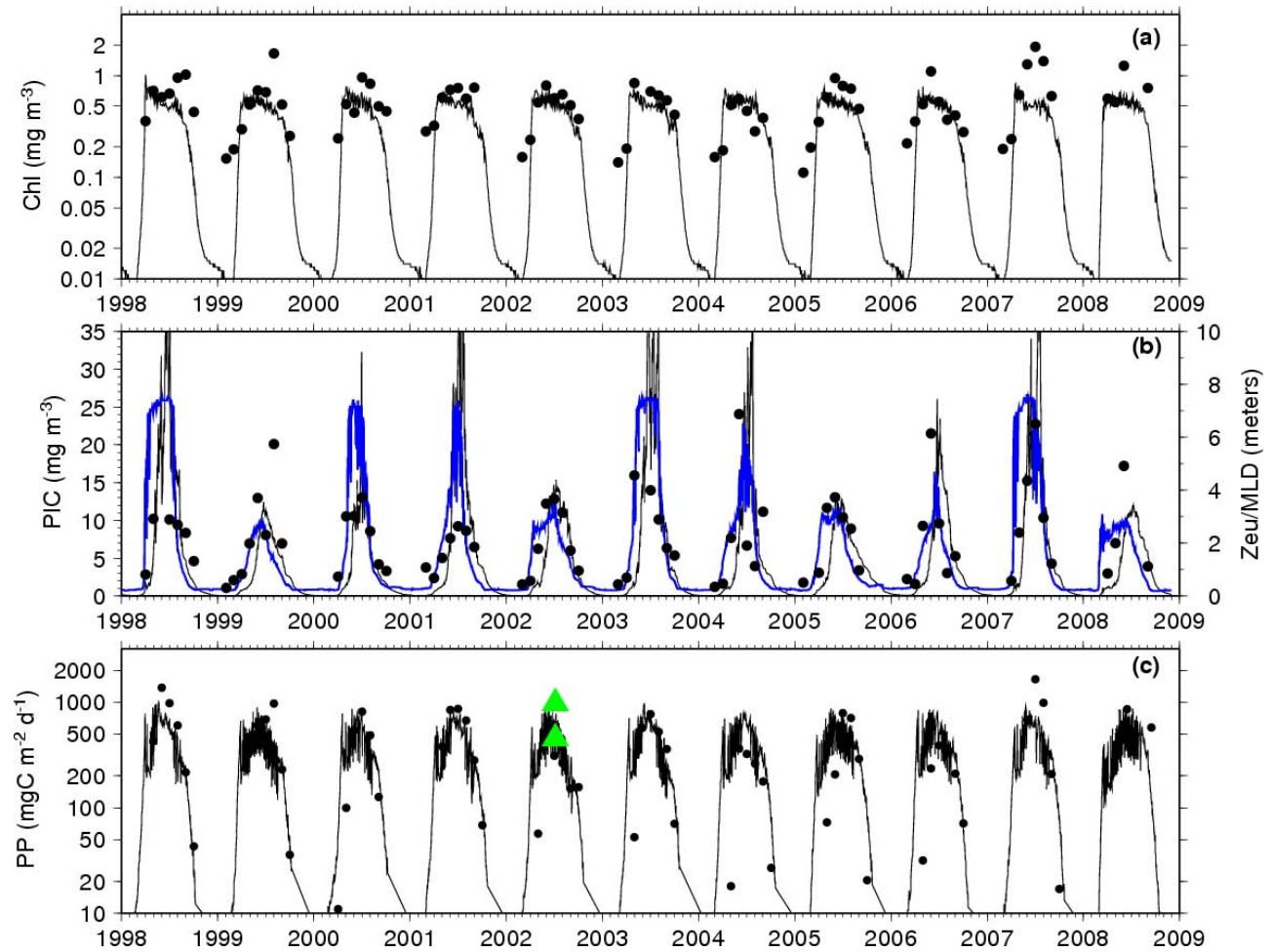

Fig. 8. Time series of model versus satellite-derived Chl a, PIC (b), and PP (c). The black lines are the daily model parameters. The black dots in (a) and (b) are monthly SeaWiFS standard products, while the black dots in (c) are monthly satellite-derived CbPM PP values. The blue line time series in panel (b) is the model-derived euphotic depth to mixed layer thickness ratio (Zeu/MLD), and the two green triangles are PP values from in situ C-14 incubations. Note that the $\mathrm{y}$-scales for $\mathrm{Chl}$ and PP are logarithmic.

Table 1. Tabulated values show comparisons between observed and modeled mean DIC, TA, 1026 and surface ocean $p \mathrm{CO}_{2}$. Values are for the reference (Experiment A), no relaxation (Experiment B), and abiotic (Experiment C) runs. Only daily model values matching the nearest observed dates were included. Differences between model experiments and observed values $(\Delta \mathrm{d})$ are also included. The time periods for averaging are 1991-2007 for DIC, 1997-2007 for TA, and 1993-2007 for pCO2.

\begin{tabular}{llllllll}
\hline Variable & Observed & $\mathrm{A}$ & $\Delta \mathrm{d}$ & $\mathrm{B}$ & $\Delta \mathrm{d}$ & $\mathrm{C}$ & $\Delta \mathrm{d}$ \\
\hline $\mathrm{DIC}$ & 2111.01 & 2106.87 & -4.14 & 2095.93 & -15.08 & 2122.74 & +11.73 \\
$\mathrm{TA}$ & 2309.26 & 2307.82 & -1.44 & 2303.82 & -5.44 & 2303.89 & -5.37 \\
$\mathrm{pCO}_{2}$ & 347.65 & 350.61 & +2.96 & 332.30 & -15.35 & 391.55 & +43.90 \\
\hline
\end{tabular}

Despite having significant $R$ values, the model has somewhat larger nitrate $\sigma^{*}$ than the observed reference. Time series of observed and model nutrients (Fig. 9 in Sect. 6) reveal that the model underestimates all nutrients during 20052006, especially nitrate. However, the low winter nutrients are consistent with warmer winter SSTs, as given by both model and observations (Fig. 10 in Sect. 6), and consequently shallower MLDs. Since these are the only two years during which the model underestimates nutrients, it is possible that the monthly mean physical fields and monthly climatological nutrients used to derive the forcing for the model were of insufficient resolution for capturing the smaller scale variability responsible for nutrient enhancement that occurred during those two years. Surface ocean $p \mathrm{CO}_{2}$ references are in good agreement with the model $\left(R \sim 0.7\right.$ and $\left.\sigma^{*} \sim 1.0\right)$. Finally, the model PP provides good agreement with the PP estimates derived with satellite-based CbPM (Fig. 8 in Sect. 6) using SeaWiFS data at the precise location of the model simulation $\left(r^{2}=0.68\right)$.

\section{Sensitivity runs}

In order to evaluate the effects of model forcing and biological uptake of carbon on the model results, a couple of sensitivity runs (Experiments B and C) were performed and compared with the baseline run (reference, Experiment A), which was conducted following the description given in 2.2. One of the sensitivity runs (Experiment B) was conducted without 

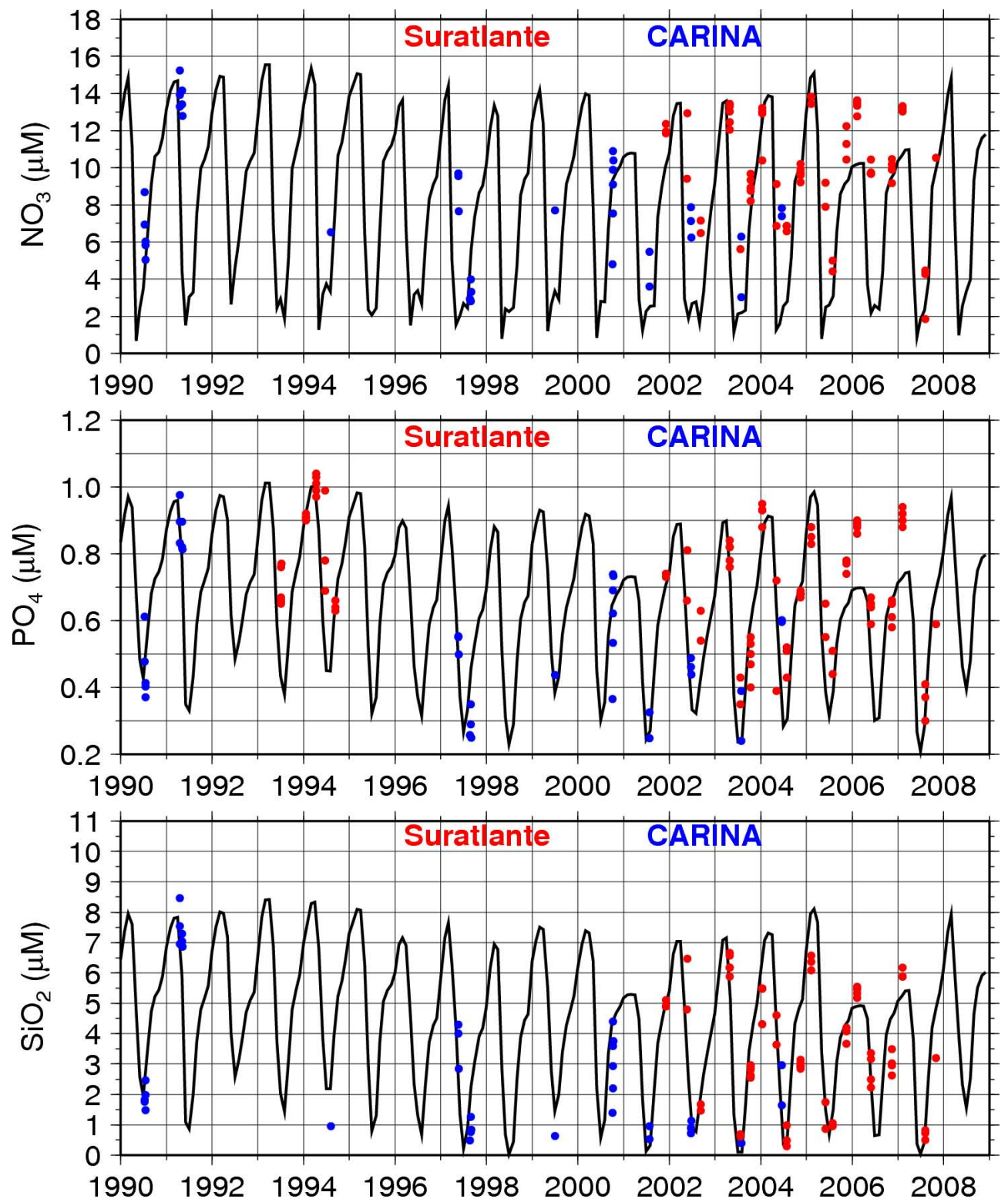

Fig. 9. Time series of model surface nutrients $\left(\mathrm{NO}_{3}, \mathrm{PO}_{4}, \mathrm{SiO}_{2}\right)$ with corresponding in situ observations from Suratlante (red dots) and CARINA (blue dots).

the relaxation of DIC and TA to the empirical values derived from the data. In addition, the deep water trend in DIC was turned off and deep water values of DIC and TA were maintained constant and equal to their initial values. The second sensitivity run (Experiment C) consisted of maintaining the DIC and TA forcing strategy used in the reference run but with the biological effects turned off, i.e., abiotic ocean case.

Four surface ocean carbon-related variables were analyzed: DIC, TA, $p \mathrm{CO}_{2}$, and air-sea $\mathrm{CO}_{2}$ flux. The climatologic (1981-2008) seasonal variability of these variables is shown in Fig. 7a. There are notable differences between the three different model experiments. Although Experiment B (without relaxation and DIC bottom trend) differs slightly from the reference, the largest differences are apparent in the abiotic run (Experiment $\mathrm{C}$ ), since the biological sources and sinks that affect the DIC and TA seasonality were turned off in the model. These are the net community production, which is a sink for DIC ( $\mathrm{CO}_{2}$ uptake) and source for TA (nitrate uptake consumes hydrogen ions), dissolution (source for both DIC and TA) and $\mathrm{CaCO}_{3}$ production (sink for both DIC and TA). With these terms turned off, only thermodynamic and vertical mixing effects are at work in the model and that is reflected in the seasonal changes of DIC, TA, $p \mathrm{CO}_{2}$, and $\mathrm{CO}_{2}$ flux. Note that without the biology (Experiment $\mathrm{C}$ ), the ocean becomes a source of $\mathrm{CO}_{2}$ for most of the year, while the reference run (Experiment $\mathrm{A}$ ), which agrees 

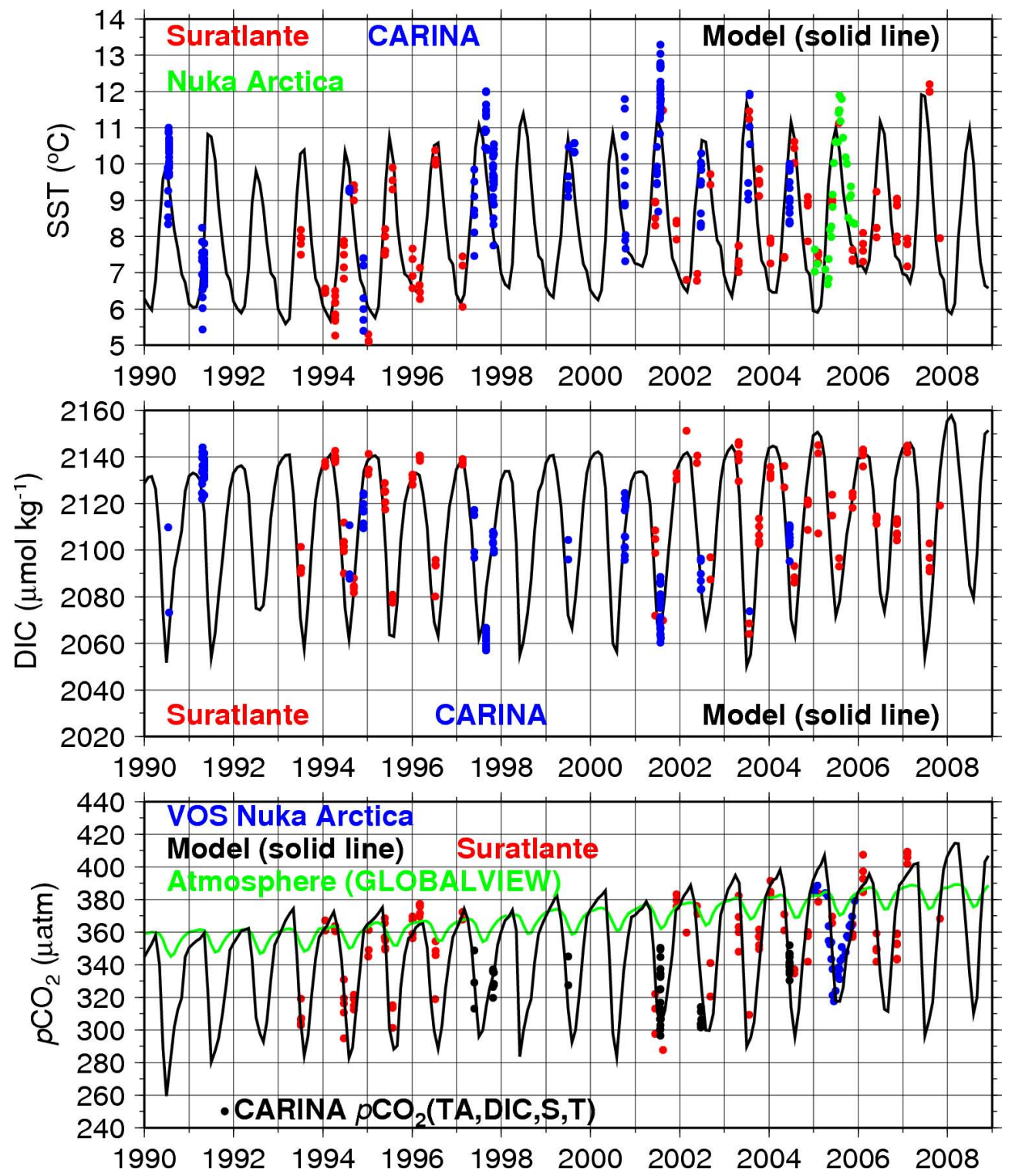

Fig. 10. Time series of model SST and surface ocean DIC and $p \mathrm{CO}_{2}$. Corresponding in situ measurements are shown with their diverse origin color-coded. The surface ocean $p \mathrm{CO}_{2}$ (bottom tier) also shows the GLOBALVIEW atmospheric $p \mathrm{CO}_{2}$ and the ocean $p \mathrm{CO}_{2}$, derived from CARINA TA, DIC, temperature and salinity.

best with observations (see next section), shows an ocean that is a sink of $\mathrm{CO}_{2}$ for most of the year and a small source during April-May. This result agrees with previous studies that show that biology is critical to these seasonal changes at this location and that vertical mixing also plays a major role (Takahashi et al., 1993, 2002, 2009; Ullman et al., 2009; Bennington et al., 2009; Metzl et al., 2010). The annual mean values of $p \mathrm{CO}_{2}$ and air-sea $\mathrm{CO}_{2}$ flux derived from the reference, no relaxation, and abiotic runs (Experiments A, B, and $\mathrm{C}$, respectively) are 337.0, 325.6, 371.0 $\mu \mathrm{atm}$, and +7.3 , $+12.5,-1.7 \mathrm{mmol} \mathrm{C} \mathrm{m}^{-2} \mathrm{~d}^{-1}$, respectively. Further comparison between mean DIC, TA, and surface ocean $p \mathrm{CO}_{2}$ from observed values and model experiments shows significant differences between Experiments A, B and C when compared to observations. In this comparison only daily values nearest to the time of observations were included. The time periods for averaging were 1991-2007 for DIC, 1997-2007 for TA, and 1993-2007 for $p \mathrm{CO}_{2}$. The results are summarized in Table 1, which shows significant increase in the biases for the no relaxation (Experiment $\mathrm{B}$ ) and abiotic (Experiment $\mathrm{C}$ ) runs when compared to the reference run (Experiment A). For example, The biases for surface ocean $p \mathrm{CO}_{2}$ are $+3 \mu \mathrm{atm},-15 \mu \mathrm{atm}$, and $+44 \mu \mathrm{atm}$ for Experiments A, B, and $\mathrm{C}$, respectively.

The difference in interannual variability of surface DIC and ocean $p \mathrm{CO}_{2}$ from two of the model experiments, one 
Table 2. Summary of surface-ocean observed and model (reference run) mean values and standard deviations (STD) for a selected number of variables. Only daily model values matching the nearest observed dates were included.

\begin{tabular}{|c|c|c|c|c|c|}
\hline \multirow[t]{2}{*}{ Variable } & \multicolumn{2}{|c|}{ Observed } & \multicolumn{2}{|c|}{ Model } & \multirow[t]{2}{*}{$\mathrm{N}$} \\
\hline & Mean & STD & Mean & STD & \\
\hline $\operatorname{SST}\left({ }^{\circ} \mathrm{C}\right)$ & 9.02 & 1.77 & 8.92 & 1.71 & 372 \\
\hline $\mathrm{TA}(\mu \mathrm{mol} \mathrm{kg}-1)$ & 2309.26 & 8.88 & 2307.82 & 2.61 & 185 \\
\hline DIC $(\mu \mathrm{mol} \mathrm{kg}-1)$ & 2111.01 & 24.42 & 2106.87 & 27.53 & 243 \\
\hline $\mathrm{NO}_{3}(\mu \mathrm{M})$ & 9.38 & 3.27 & 7.00 & 4.68 & 102 \\
\hline $\mathrm{SiO}_{2}(\mu \mathrm{M})$ & 3.36 & 2.14 & 3.82 & 2.26 & 103 \\
\hline $\mathrm{PO}_{4}(\mu \mathrm{M})$ & 0.66 & 0.21 & 0.62 & 0.22 & 122 \\
\hline$p \mathrm{CO}_{2}(\mu \mathrm{atm})$ & 347.65 & 26.21 & 350.61 & 31.18 & 199 \\
\hline Sat PP $\left(m g C m^{-2} d^{-1}\right)$ & 207.85 & 323.19 & 220.63 & 235.28 & 114 \\
\hline
\end{tabular}
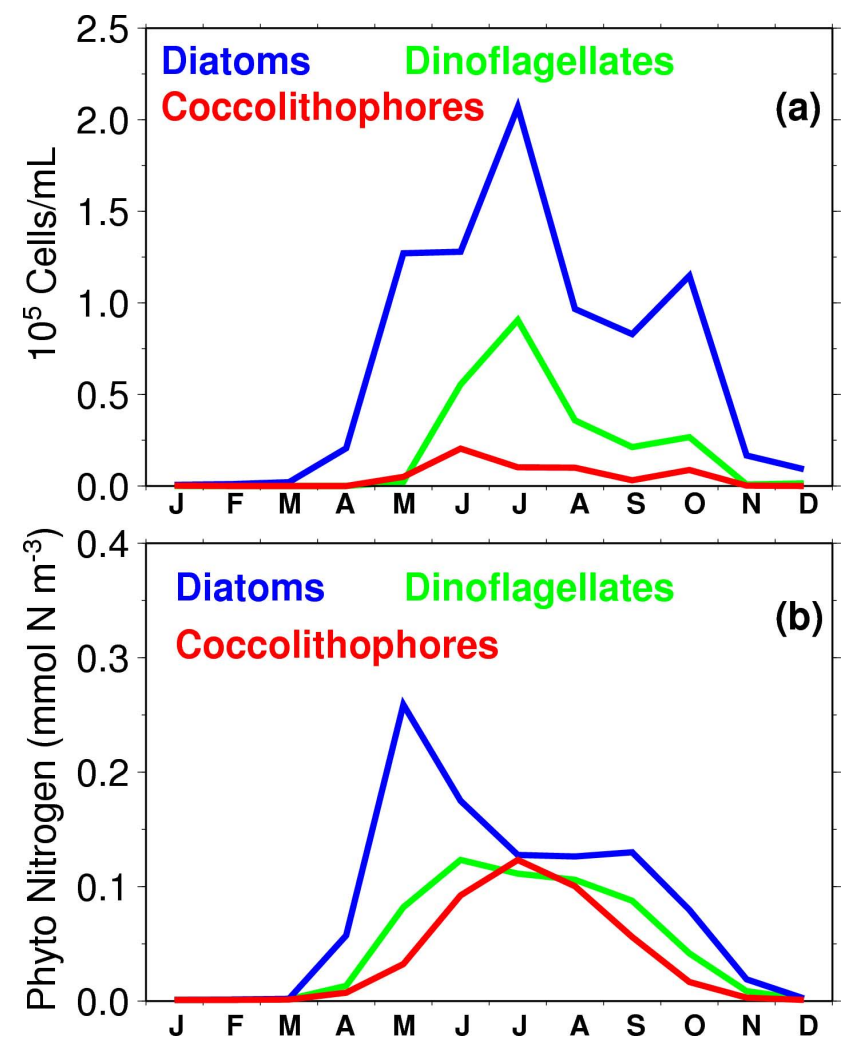

Fig. 11. Seasonal cycles of in situ CPR cell counts for diatoms, dinoflagellates, and coccolithophores (a), and model nitrogen-based concentrations of the same functional groups (b).

including deep water DIC and TA relaxation and bottom DIC trend (Experiment $\mathrm{A})$ and one without it (Experiment $\mathrm{B}$ ), is shown in Fig. 7b. The available data are also shown for comparison. There is a striking difference between these two experiments. Experiment A shows a very good match with the available data, while the results from Experiment B have a very poor agreement with the data, including a significant reduction in the seasonal amplitude of DIC and $p \mathrm{CO}_{2}$. This result illustrates the degree to which the model results are di-

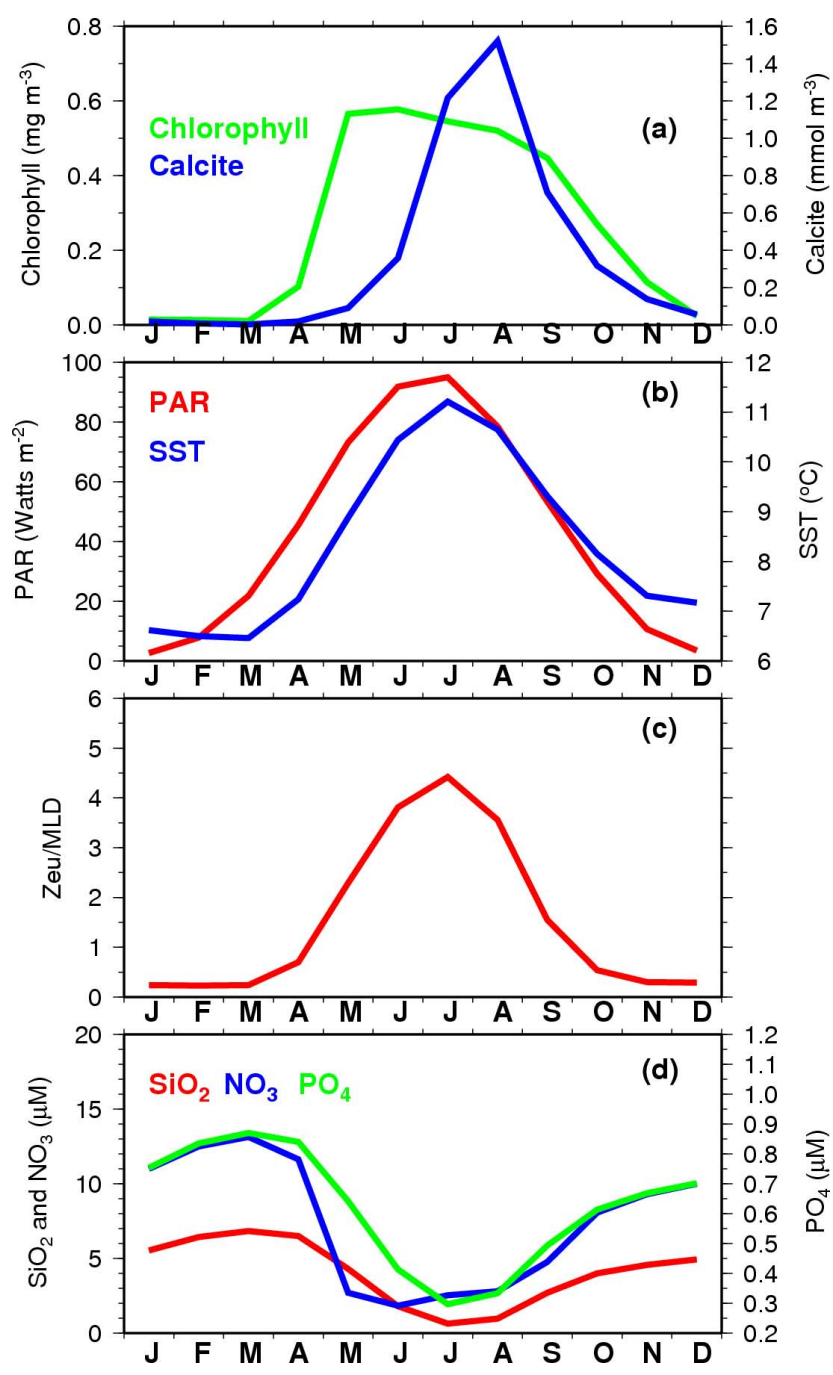

Fig. 12. Seasonal cycles of Chl $a$ and calcite (a), PAR and SST (b), Zeu:MLD ratio (c), and nutrients (d). 

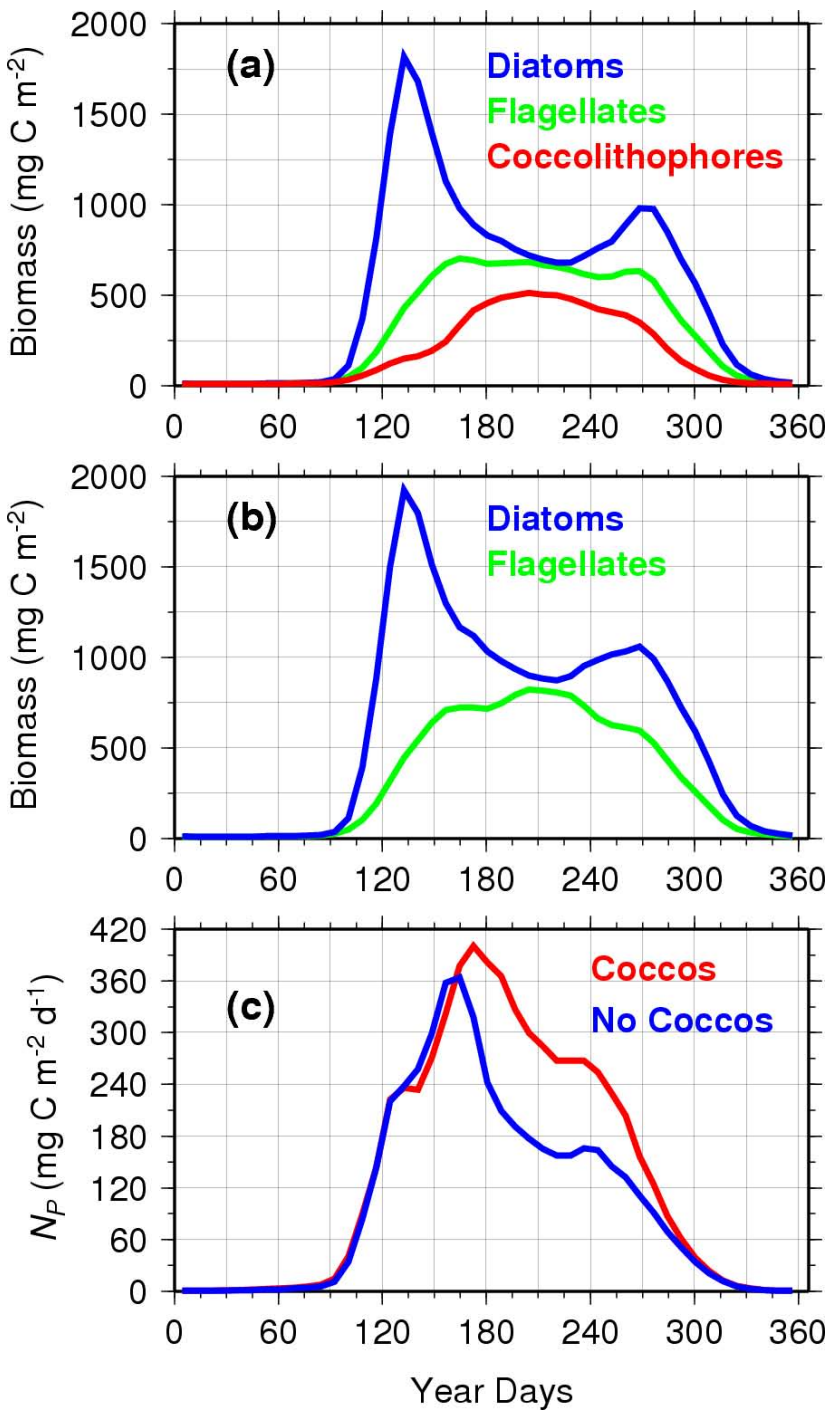

Fig. 13. Seasonal concentration of phytoplankton functional groups biomass with and without the presence of coccolithophores (a and b, respectively), and net community production with and without coccolithophores (c).

rectly a function of the setting of DIC, TA and nutrients at $>200 \mathrm{~m}$, how much the deep reservoir impacts surface behavior, and more clearly that it is very important to be included in the model to appropriately represent the interannual variability driven by non-local processes.

\section{Discussion}

\subsection{Seasonal and interannual variability}

Figure 8 shows a 1998-2008 time series of model and satellite-derived Chl $a$, calcite concentration (PIC), and PP. The ratio of euphotic depth to mixed layer depth (Zeu/MLD) derived from the model is shown by the blue line, super- posed to the PIC time series. This ratio provides a measurement of how much of the daily light exposure the phytoplankton experiences during the growth season. Apparently, every year the most productive periods (when Zeu is shallowest) occur during highly stratified conditions (with shallow MLDs). That is an indication that light availability for photosynthesis is a major limiting factor, causing seasonal variability of phytoplankton growth and probably also affecting the species succession in the region (Nanninga and Tyrrell, 1996; Tyrrell and Taylor, 1996).

Overall, the model agrees well with the corresponding satellite-derived products. In fact, the model reproduces the satellite PIC interannual variability rather well, albeit with the model showing a tendency to produce peak PIC concentration higher and later than the satellite observations. Notably, the interannual changes in peak PIC concentrations are correlated with light intensity, as they follow the variability of the Zeu/MLD ratio. The variability in this ratio is primarily driven by changes in MLD, since the standard deviation in MLD during the summer months (June-July-August, 1981-2008) is about 10 times larger than the standard deviation in Zeu ( $24.8 \pm 10.8 \mathrm{~m}$ and $72.6 \pm 1.4 \mathrm{~m}$, respectively). The growth of calcite-forming coccolithophores in the model is, by design, three times more demanding on light exposure than the other two functional groups, since it has the lowest assigned $\mathrm{P}$ vs. I initial slope of $0.033\left(\mathrm{Wm}^{-2}\right)^{-1} \mathrm{day}^{-1}$ (see Table B2). The coherent model prediction of growth of coccolithophores and the variations in PIC concentration are consistent with the interannual changes in PIC observed by the satellite, which confirms the relevance of the Zeu/MLD ratio.

Time series of model and in situ measurements of nutrients $\left(\mathrm{NO}_{3}, \mathrm{PO}_{4}\right.$, and $\left.\mathrm{SiO}_{2}\right)$ for the time period, for which there are data (1990-2008), are shown in Fig. 9; SST and surface ocean DIC and $p \mathrm{CO}_{2}$ for the same time period are shown in Figure 10, also with corresponding in situ measurements. The GLOBALVIEW atmospheric $p \mathrm{CO}_{2}$, which was used to calculate $\Delta p \mathrm{CO}_{2}$ and sea-air $\mathrm{CO}_{2}$ flux, is shown in the bottom panel of Fig. 10 along with the surface ocean $p \mathrm{CO}_{2}$. The seasonal and interannual changes in nutrients and carbon are substantial and driven primarily by changes in biological production, vertical mixing, SST, and sea-air $\mathrm{CO}_{2}$ flux.

The observed and model seasonal partitioning of phytoplankton functional groups (diatoms, dinoflagellates, and coccolithophores) are shown in Fig. 11. The observed seasonality originates from the aggregated, monthly-averaged indices of phytoplankton groups from the CPR data (cell counts) in the standard area B6, south of Iceland (Fig. 11a). The size of standard area B6 is relatively large $\left(59^{\circ} \mathrm{N}\right.$ to $64^{\circ} \mathrm{N} ; 19^{\circ} \mathrm{W}$ to $31^{\circ} \mathrm{W}$ ), so some spatial smoothing is to be expected. The model shows (Fig. 11a) that diatoms are the most abundant functional group, with a large bloom in early spring and a secondary bloom in fall. The diatom bloom is followed by blooms of dinoflagellates and coccolithophores. 

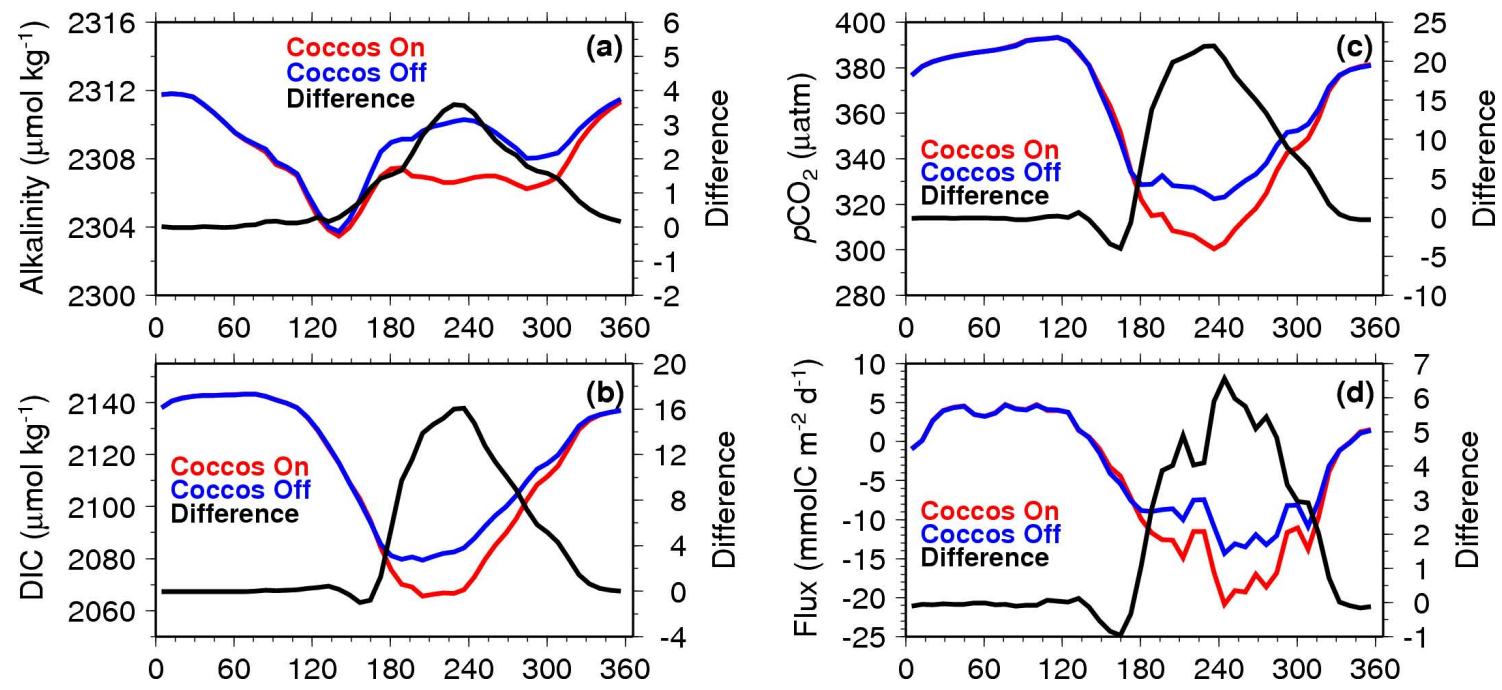

Fig. 14. Seasonal (1998-2008) changes of alkalinity (a), DIC (b), surface ocean $p \mathrm{CO}_{2}$ (c), and sea-air $\mathrm{CO}_{2}$ flux (d) with (red) and without (blue) coccolithophores. The black line is the difference.

The double diatom peak is also present in the model nitrogenbased concentrations of the functional groups (Fig. 11b). The abundance of coccolithophores in the CPR data is only a fraction of what one may expect, due to the small size of the organisms $(5 \mu \mathrm{m})$ compared to the size of the mesh used $(250 \mu \mathrm{m})$. The CPR data are however a relevant index of the relative annual changes and thus reveal the blooming of coccolithophores. The nitrogen-based concentration of coccolithophores in the model is thus much more substantial and in line with the findings of previous field work studies in the northeast North Atlantic, reporting large concentrations of coccolithophores during the summer bloom. For example, Fernandez, et al. (1993) reported a total estimated coccolithophore $\mathrm{C}$ biomass as large as $50 \%$ of the total phytoplankton $\mathrm{C}$ biomass.

\subsection{Biogeochemical response to physical forcing}

The seasonal changes in biogeochemical properties as a result of physical forcing are given in Fig. 12, which shows the model seasonal cycles of chlorophyll, calcite (PIC), SST, PAR, the ratio of euphotic depth to MLD (Zeu/MLD), and nutrients $\left(\mathrm{NO}_{3}, \mathrm{PO}_{4}\right.$, and $\left.\mathrm{SiO}_{2}\right)$. The rise of Chl $a$ starts in April, when the Zeu/MLD ratio is $\sim 0.5$ and a drawdown of nutrients ensues. That is as one may expect, according to the Sverdrup (1953) theory on vernal blooming of phytoplankton, as the critical depths in oceanic environments are several times that of the Zeu.

The PIC concentration starts to rise in May when the Zeu/MLD has reached $\sim 2$. The broad peak in the total Chl $a$ from all three functional groups extends from May to September, associated with shallower MLDs (Zeu/MLD ratio $>2.0$ ). Depletion of available light and nutrients for growth and an increase of grazing pressure reduce biomass significantly during the summer. The growth season cycle is completed during autumn, as wind stress increases the vertical mixing, promoting nutrient renewal. The coccolithophore bloom, indicated by the changes in PIC concentration due to calcite production, peaks in July-August, when light conditions $(\mathrm{Zeu} / \mathrm{MLD}$ ratio $>4.0$ ) provide favorable conditions for the bloom-forming coccolithophore Emiliania huxleyi, a species well-known to the area (Balch et al., 1992; Fernandez et al., 1993; Holligan et al., 1993a; Holligan et al., 1993b). As the MLD deepens and light (PAR) levels are significantly reduced, Chl $a$ and PIC concentrations drop gradually after September. The model confirms established ideas of the interplay of light availability, vigorous winter mixing/summer restratification, and nutrient availability, which are central to the classical North Atlantic spring bloom (Nanninga and Tyrrell, 1996; Tyrrell and Taylor, 1996).

\subsection{Impact of phytoplankton blooms on carbon uptake}

To evaluate the impact of phytoplankton groups on the uptake of carbon, we conducted a model experiment with the coccolithophore components turned off (no carbonate pump) and compared the results with the baseline experiment (biological and carbonate pumps), including all three functional groups (diatoms, dinoflagellates, and coccolithophores). The results are shown in Figures 13 and 14 as seasonal 8-day climatologic averages for 1998-2008. In Figure 13 we see the results of seasonal changes in the upper $120 \mathrm{~m}$ verticallyintegrated phytoplankton biomass concentrations with and without the presence of coccolithophores (Fig. 13a and b, respectively), and the corresponding changes in net community production (Fig. 13c). In the presence of coccolithophores, the yearly-averaged integrated biomass for diatoms, dinoflagellates, and coccolithophores was 534, 
318, and $184 \mathrm{mg} \mathrm{Cm}^{-2}$, respectively. The corresponding model-derived $N p$ with all three functional groups was $134 \mathrm{mg} \mathrm{C} \mathrm{m}^{-2} \mathrm{~d}^{-1}$. With the exclusion of coccolithophores, the population of diatoms increased to an integrated value of $613 \mathrm{mg} \mathrm{C} \mathrm{m}^{-2}$ and dinoflagellates to $341 \mathrm{mg} \mathrm{C} \mathrm{m}^{-2}$, respectively. However, there was a net decrease in $N p$ to $104 \mathrm{mg} \mathrm{C} \mathrm{m}^{-2} \mathrm{~d}^{-1}$ (or a $22.4 \%$ decrease). At first glance, it would be expected that the diatoms and dinoflagellates would benefit from the absence of coccolithophores and have additional nutrients to draw from and increase their combined production. However, the explanation lies in the carbon uptake efficiency of coccolithophores when compared to the other two groups. In equation B35 of Appendix B, it can be seen that, for the baseline run, dinoflagellates and diatoms have a Redfield C:N (6.625), while coccolithophores have a higher C:N (9.4), which is an average, based on the range of 5.81 to 13.05 reported by Fernandez et al. (1993). The diatoms and dinoflagellates do pick up some of the slack but not entirely, because the coccolithophores uptake carbon $42 \%$ more efficiently (100[1-9.4/6.625)). In addition, the peak demand of nutrients does not overlap among the three functional groups, as the maximum productive time periods of each group are not in phase. So the absence of coccolithophores is less influential on the availability of nutrients for the other two groups. This seems to be a consistent explanation of why the removal of coccolithophores from the model results in the reported differences in PP and $p \mathrm{CO}_{2}$ drawdown.

A couple of sensitivity tests were conducted to assess the effect of changing the $\mathrm{C}: \mathrm{N}$ ratio for coccolithophores in the model. We used two values of $\mathrm{C}: \mathrm{N}$ ratio for coccolithophores in the model, Redfield $(R 1=6.625)$, and twice the Redfield ratio $(R 2=13.25)$. The annual mean $(1998-$ 2008) results from $\mathrm{R} 1$ for the following key model parameters, $p \mathrm{CO}_{2}$, DIC, TA, air-sea $\mathrm{CO}_{2}$ flux, net community production, $\mathrm{CaCO}_{3}$ concentration, and PIC production are $358.8 \mu \mathrm{atm}, 2114.6 \mu \mathrm{mol} \mathrm{kg}-1,2308.3 \mu \mathrm{mol} \mathrm{kg}{ }^{-1}$, $4.4 \mathrm{mmol} \mathrm{C} \mathrm{m}^{-2} \mathrm{~d}^{-1}, 123.6 \mathrm{mg} \mathrm{C} \mathrm{m}^{-2} \mathrm{~d}^{-1}, 3.3 \mathrm{mg} \mathrm{m}^{-3}$, and $4.9 \mathrm{mg} \mathrm{C} \mathrm{m}^{-2} \mathrm{~d}^{-1}$. The equivalent values in the same units for experiment R2 are $353.7(-5.1), 2111.3(-3.3), 2308.0$ $(-0.3), 5.73(+131 \%), 146.1(+118 \%), 6.7(+200 \%)$, and $9.8(+200 \%)$. So the model is very sensitive to changes in the C:N ratio for coccolithophores.

The $22 \%$ reduction in $N p$ between the baseline run $(\mathrm{C}: \mathrm{N}=9.4$ for coccolithophores) and the baseline run without coccolithophores has consequences in the biological uptake of carbon. Figure 13 shows that, without the net community production and calcification by coccolithophores, at the peak of the biological drawdown, the alkalinity (Fig. 14a) increases by up to $4 \mu \mathrm{mol} \mathrm{kg}{ }^{-1}$ with a corresponding increase in DIC (Fig. 14b) of up to $16 \mu \mathrm{mol} \mathrm{kg}^{-1}$. As a result, the net effect of the absence of the coccolithophores bloom is an increase in $p \mathrm{CO}_{2}$ of more than $20 \mu \mathrm{atm}$ (Fig. 14c). The largest differences occur from July to October, which translate into $\Delta p \mathrm{CO}_{2}$ differences ranging from $24 \%$ to $35 \%$ during this period. The seasonal changes in the sea-air $\mathrm{CO}_{2}$ flux are shown in Fig. 14d. At the peak of the bloom, the exclusion of coccolithophores causes a reduction of $\mathrm{CO}_{2}$ uptake of more than $6 \mathrm{mmol} \mathrm{m}^{-2} \mathrm{~d}^{-1}$. On average, the impact of coccolithophores on air-sea $\mathrm{CO}_{2}$ flux is $27 \%$. This result highlights the importance of including all major functional groups in the modeling of carbon variability in the subpolar North Atlantic. Some sensitivity tests were conducted using different gas transfer coefficients $(k)$. The baseline run uses a value of 0.31 (Wanninkhof, 1992), as indicated in Eq. (B39) in Appendix B. A value of $k=0.27$ (Sweeney et al., 2009) was used to evaluate the model sensitivity of air-sea $\mathrm{CO}_{2}$ flux to different gas transfer coefficients. A reduced $\mathrm{CO}_{2}$ ocean uptake of $\sim 7 \%$ is obtained with the experiment using $k=0.27$, when compared with the experiment using $k=0.31$, with both experiments including coccolithophores. Model experiments using $k=0.27$ with and without coccolithophores indicate that the exclusion of coccolithophores causes a reduced $\mathrm{CO}_{2}$ ocean uptake of $\sim 28 \%$, a small difference ( $1 \%$ ) compared to the use of $k=0.31$.

Suykens et al. (2010) reported the carbon uptake impact of coccolithophore blooms in the northern Bay of Biscay based on DIC and alkalinity observations. They concluded that the decrease of DIC (and increase of $p \mathrm{CO}_{2}$ ) due to net community calcification was overwhelmingly lower than the decrease of DIC (and decrease of $p \mathrm{CO}_{2}$ ) due to net community production, a clear indication of the importance of coccolithophore blooms in the uptake of atmospheric $\mathrm{CO}_{2}$ in the North Atlantic, where blooms of coccolithophores are the most intense and recurrent.

A spatial assessment on the reduction in uptake of atmospheric $\mathrm{CO}_{2}$ under the exclusion of coccolithophores was made for the regional domain of the Irminger and Icelandic Basins. The region considered is bound by $44^{\circ} \mathrm{W}-8^{\circ} \mathrm{W}$ and $56^{\circ} \mathrm{N}-65^{\circ} \mathrm{N}$, and by depths greater than $200 \mathrm{~m}$ to exclude coastal regions of Iceland and Greenland. The monthly areal (in $\mathrm{m}^{2}$ ) extent of the bloom was determined using SeaWiFS monthly composites within the above boundaries and considering only pixels with PIC concentrations larger than $5 \mathrm{mg} \mathrm{m}^{-3}$, a value arbitrarily picked as the threshold of significant influence of coccolithophore blooms in the drawdown of atmospheric $\mathrm{CO}_{2}$ (monthly concentrations range from 0 to $27 \mathrm{mg} \mathrm{m}^{-3}$ ). For comparison, a threshold of $2 \mathrm{mg} \mathrm{m}^{-3}$ in PIC concentration increases the flux estimate by about $12 \%$ (or about 180 tonnes $\mathrm{Cyr}^{-1}$ ). The monthly $\mathrm{CO}_{2}$ flux difference was derived from the product of satellite area and the flux difference shown in Fig. 14d. The annual mean flux difference was estimated at nearly 1500 tonnes $\mathrm{C} \mathrm{yr}^{-1}$.

The seasonal drawdown of surface ocean $p \mathrm{CO}_{2}$ is a result of two competing effects, i.e., temperature warming and biological uptake effects. Takahashi et al.(2002) developed a method to separate these two effects for the global oceans. The effect of biology $\left(B_{\mathrm{e}}\right)$ on the surface ocean $p \mathrm{CO}_{2}$ in a given area is represented by the seasonal amplitude of $p \mathrm{CO}_{2}$, corrected to the mean annual temperature in that area. The 
effect of temperature changes $\left(T_{\mathrm{e}}\right)$ on the seasonal $p \mathrm{CO}_{2}$ variations is represented by the seasonal amplitude of the mean annual $p \mathrm{CO}_{2}$, corrected to the range of observed temperatures.

$B_{e}=\left(\Delta p \mathrm{CO}_{2}\right)_{\text {bio }}=\left(p \mathrm{CO}_{2} \text { at } T_{\text {mean }}\right)_{\max }-\left(p \mathrm{CO}_{2} \text { at } T_{\text {mean }}\right)_{\text {min }}$

$T_{e}=\left(\Delta p \mathrm{CO}_{2}\right)_{\mathrm{temp}}=\left(p \mathrm{CO}_{2} \text { at } T_{\mathrm{obs}}\right)_{\max }-\left(p \mathrm{CO}_{2} \text { at } T_{\mathrm{obs}}\right)_{\min }$

where the subscripts "min" and "max" indicate the seasonal minimum and maximum values, $T_{\mathrm{obs}}$ is the observed temperature for each $p \mathrm{CO}_{2}$ value and $T_{\text {mean }}$ is the mean temperature over the entire seasonal cycle. The relative importance of the biology and temperature effects can then be expressed by the ratio $B_{\mathrm{e}} / T_{\mathrm{e}}$. Using climatologic (1981-2008) model seasonal surface ocean $p \mathrm{CO}_{2}$ and SST, we calculate the ratio $B_{\mathrm{e}} / T_{\mathrm{e}}$ as 1.92 , which means that the biology effect is nearly twice the temperature effect in the shaping of the seasonal $p \mathrm{CO}_{2}$ variability at the model location.

Although it is not straightforward to infer to what extent the model results from a single location in the subpolar North Atlantic are representative of the North Atlantic in general, previous studies have shown coherence of results in much broader regions of the North Atlantic. For example, McKinley et al. (2011) have shown that the North Atlantic can be separated in three large biogeographic regions ("biomes") in terms of surface ocean $p \mathrm{CO}_{2}$ variability. These biomes were assigned on the basis of annual maximum mixed layer depth, annual mean SeaWiFS Chl $a$, and SST. Namely, the North Atlantic was divided into a northern seasonally stratified gyre (SP-SS) biome, a southern permanently stratified subtropical gyre (ST-PS) biome, and a seasonally stratified subtropical (ST-SS) biome. For a 29 yr-long observational period (1981-2009), the surface ocean $p \mathrm{CO}_{2}$ trends converge with the atmospheric growth for all 3 biomes, which occupy $87 \%$ of the total area of the North Atlantic. When a shorter time scale (1993-2005) is considered, the three biomes have different trends, but the SP-SS biome itself has a significant geographic extension, including a large region south of Iceland, and the Irminger, Icelandic, and Norwegian Seas. Our 1-D model location lies within the SP-SS biome and therefore is representative of surface ocean $p \mathrm{CO}_{2}$ decadal variability for that region. However, for shorter time scales, more significant regional differences are likely to occur.

\section{Summary and conclusions}

A 1-D ecosystem model was developed to assess the relative contribution of phytoplankton functional types to atmospheric $\mathrm{CO}_{2}$ uptake. Using a Taylor diagram, skill assessment of model versus field measurements reveals high scores for the majority of biogeochemical parameters, for which in situ data are available.

The seasonal patterns of phytoplankton concentrations are a response to the interplay between light availability, vigorous winter mixing/summer restratification, and nutrient availability, not unlike the classical North Atlantic spring bloom (Ducklow and Harris, 1993; Weeks et al., 1993). Functional groups compete seasonally for ideal growth conditions (Litchman et al., 2007; Sambrotto et al., 1993; Sieracki et al., 1993). Model results indicate that the springsummer bloom consists predominantly of diatoms, with still significant but less intense blooms of dinoflagellates and coccolithophores. The model shows that the diatom biomass peaks in May, with a secondary and less intense bloom in September. The dinoflagellates and coccolithophores peak in July through August, during which drawdown of surfaceocean $\mathrm{CO}_{2}$ reaches its maximum value. The effect of biological changes in the surface ocean $p \mathrm{CO}_{2}$ exceeds the temperature effect by a factor of almost 2 , a clear indication of the importance of phytoplankton photosynthesis on the uptake of atmospheric $\mathrm{CO}_{2}$ in the region, a result that is in agreement with previous studies (Takahashi et al., 1993, 2002, 2009; Ullman et al., 2009; Bennington et al., 2009; Metzl et al., 2010).

Model experiments were conducted to investigate the seasonal changes in phytoplankton concentration with and without the presence of coccolithophores, and their impact on carbon uptake. Without the influence of coccolithophore blooms, the alkalinity increases by almost $4 \mu \mathrm{mol} \mathrm{kg}^{-1}$ and DIC is elevated by up to $16 \mu \mathrm{mol} \mathrm{kg}{ }^{-1}$. The net effect of coccolithophores blooms is a drawdown in $p \mathrm{CO}_{2}$ of up to about $20 \mu$ atm during summer, with a corresponding increase of atmospheric $\mathrm{CO}_{2}$ uptake of about $6 \mathrm{mmol} \mathrm{m}^{-2} \mathrm{~d}^{-1}$, an indication of the importance of including all major phytoplankton functional groups when modeling the biological carbon pump variability in the subpolar North Atlantic.

\section{Appendix A}

\section{Ice-ocean model description (GPOMZ)}

The ocean model is hydrostatic and Boussinesq and uses a generalized vertical coordinate system, as described by Mellor et al. (2002) with a modified scalar advection scheme to avoid overshooting at sharp fronts (Mauritzen and Häkkinen, 1997). The equation of state is formulated in terms of in situ density (Mellor, 1991), expressed as a function of potential temperature, salinity, and pressure. The model's prognostic variables are the horizontal velocity components, potential temperature and salinity, and twice the kinetic energy, $q^{2}$ and $q^{2} l$, where $l$ is the turbulence macroscale (Mellor and Yamada, 1974, 1982). These turbulence quantities, together with the vertical velocity shear and buoyancy, determine the vertical mixing coefficients for momentum and scalar variables. The dynamic-thermodynamic ice model is coupled to the ocean model via interfacial stresses and via salinity and heat fluxes through the ice-water interface. The thermodynamic component of the ice model follows Semtner's (1976) formulation but with modifications to account for leads. The 

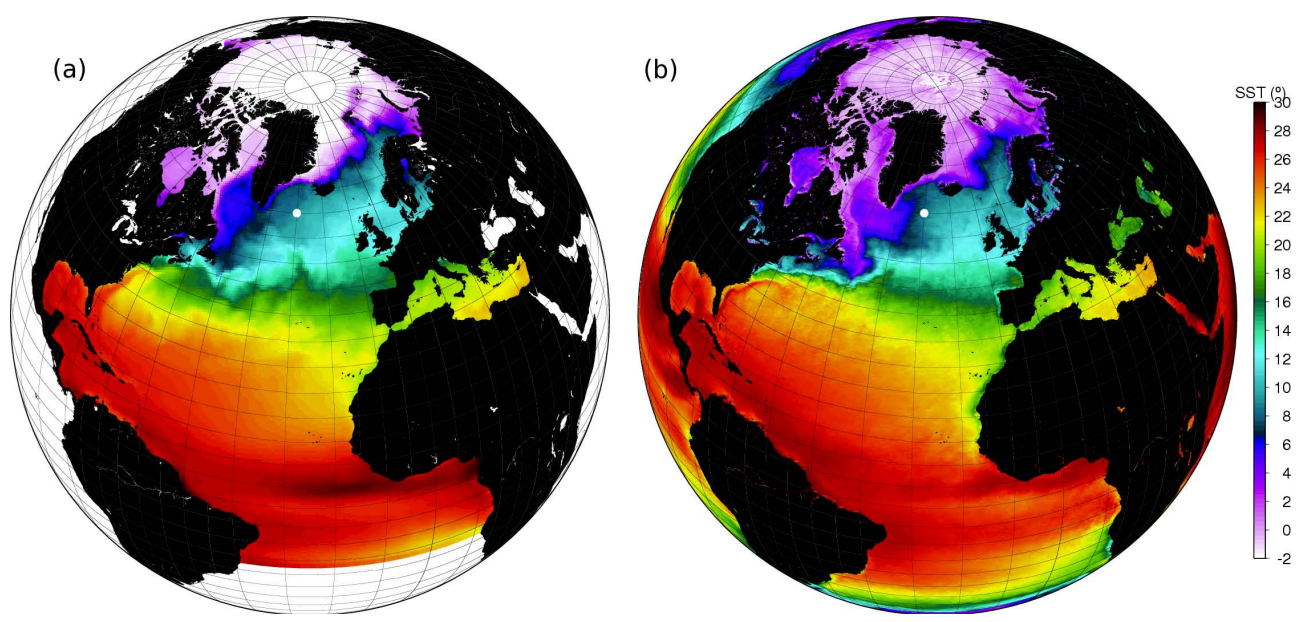

Fig. A1. Maps of GPOMZ (a) and MODIS Aqua (b) annual mean SST for 2009. Figure A1a shows the geographic domain of GPOMZ, with two open boundaries: one across the subtropical South Atlantic at $16.7^{\circ} \mathrm{S}$ and one across the Bering Strait in the Pacific sector of the Arctic Ocean. The satellite SST in Fig. A1b is included for comparison, showing that the model provides a realistic representation of all surface fronts. Regions with SST less than zero are partially to fully ice covered.

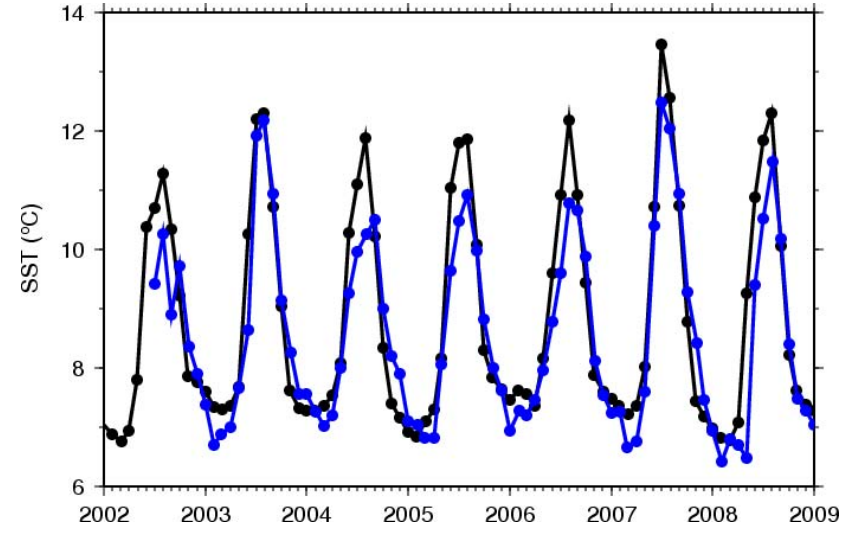

Fig. A1. Time series of monthly GPOMZ (black) and MODIS (blue) SST at the location of ECO1D-2.0 simulation $\left(60^{\circ} \mathrm{N}\right.$, $\left.30^{\circ} \mathrm{W}\right)$. GPOMZ temperature profiles were bias-corrected based on monthly WOA05 climatologic profiles. GPOMZ SST is $0.78^{\circ} \mathrm{C}$ warmer on average (1981-2008) when compared to WOA05 SST climatology. The adjusted GPOMZ SST has a $0.31{ }^{\circ} \mathrm{C}$ warm bias when compared to MODIS SST (July 2002 - December 2008), as shown in this figure.

dynamics of the ice model is described as a continuum with a generalized viscous rheology (Häkkinen, 1987; Häkkinen and Mellor, 1992).

The heat and momentum exchanges between the atmosphere and ice/ocean are computed from bulk formulae using an exchange coefficient of $1.4 \times 10^{-3}$, whereas the momentum, salt, and heat exchanges between the ice-ocean interface and the ocean interior are computed from the "law of the wall", assuming a turbulent boundary layer over a rough surface. The scheme uses the Yaglom and Kader (1974) formulation for heat and mass transfer over a rough wall,

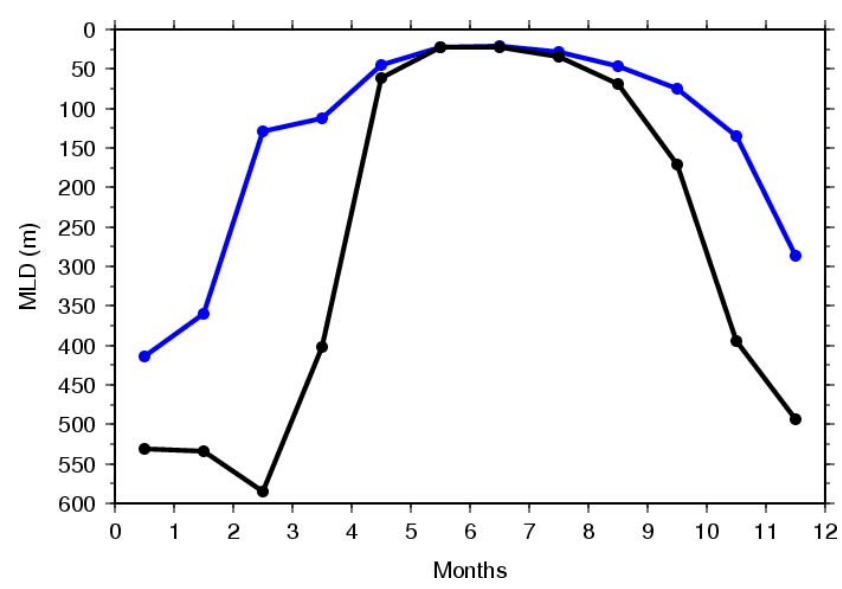

Fig. A2. Seasonal climatology of mixed layer depth (MLD) from de Boyer Montégut et al. (2004) (blue) and from GPOMZ at the ECO1D-2.0 site. There is good agreement from May to September, but GPOMZ MLD is much deeper in winter and late fall.

which gives different salt and heat resistance coefficients and a Smagorinsky scheme for the lateral viscosity and diffusivity . The vertical diffusivities for momentum and scalar quantities are computed from the turbulence closure and added to a background diffusivity of $1.0 \times 10^{-5} \mathrm{~m}^{2} \mathrm{~s}^{-1}$. The Jerlov formulation for oceanic optical water type IA (Jerlov, 1976) is used wherein $31 \%$ of the incoming short-wave radiation is absorbed below the sea surface, decreasing exponentially with depth with an extinction coefficient of $0.042 \mathrm{~m}^{-1}$. The model equations are solved using a split mode scheme and a z-level coordinate, curvilinear grid. The coupled ice-ocean model has a variable resolution of $28-56 \mathrm{~km}$ in an orthogonal curvilinear grid designed for the area. This resolution is not eddy-resolving, but is adequate for simulating large-scale 
circulation. The model domain boundary in the Atlantic sector lies at $16.7^{\circ} \mathrm{S}$ and at the Pacific side in the Bering Strait. The model topography is a smoothed version of the ETOPO5 digital database (ETOPO5, 1988). The model uses a total of 26 vertical levels as follows: $3,9,18.5,37.5,75,125,175$, $250,350,450,575,725,900,1100,1300,1500,1700,1900$, $2150,2450,2800,3250,3750,4250,4750$, and $5250 \mathrm{~m}$. Figure A1 shows maps of GPOMZ and MODIS Aqua annual mean SST for 2009. Figure A1a shows the geographic domain covered by GPOMZ. The satellite SST in Fig. A1b is included for comparison, showing that the model provides a realistic representation of all surface fronts. Regions with SST less than zero are partially to fully ice covered. Figure $\mathrm{A} 2$ shows a time series comparison between GPOMZ and MODIS SST at the location of ECO1D-2.0 simulation. Figure A3 shows the monthly seasonal MLD climatology from de Boyer Montégut et al. (2004) and from GPOMZ at the ECO1D location. There is good agreement from May to September, but the GPOMZ MLD is much deeper for the other months. The deBoyer-Montégut MLD is provided on a $2^{\circ} \times 2^{\circ}$ resolution grid with three different MLD criteria. The criterion for both MLDs in Fig. A3 is the fixed density criterion, i.e., the depth where density increase compared to density at $10 \mathrm{~m}$ equals $0.03 \mathrm{~kg} \mathrm{~m}^{-3}$.

The ocean model was initialized with the winter average hydrographic climatology derived from the Polar Science Center Hydrographic Climatology (PHC 3.0) (Steele et al., 2001). A transport of $0.8 \mathrm{~Sv}$ was specified at Bering Strait and $0.8 \mathrm{~Sv}$ out at the southern boundary. At the northern and southern boundary, the salinities and temperatures are relaxed to monthly climatological values. Climatological monthly river discharge for 474 rivers within the model domain is specified with the global river database, described by Barron and Smedstad (2002). An additional river discharge of $700 \mathrm{~km}^{3} \mathrm{yr}^{-1}$ is uniformly distributed along the Eurasian margin of the Arctic. River runoff is treated as a virtual flux of salt. The model is forced with daily NCEP/NCAR Reanalysis sea level pressure, air temperature $2 \mathrm{~m}$ above sea level, surface momentum fluxes and relative humidity for 19482011. Climatological monthly mean cloudiness is based on the ISCCP D2 data set from 1984-2004, except north of $\sim 65^{\circ} \mathrm{N}$ where a uniform monthly mean cloudiness is specified. Climatological monthly mean precipitation minus evaporation $(\mathrm{P}-\mathrm{E})$ is derived from the NCEP operational analysis (Rasmusson and Mo, 1996). An additional $1350 \mathrm{~km}^{3} \mathrm{yr}^{-1}$ of precipitation is added, and distributed with a peak value at $\sim 8^{\circ} \mathrm{N}$ to simulate the Intertropical Convergence Zone.

\section{Appendix B}

\section{Biogeochemical model description (ECO1D-2.0)}

The model features multiple functional groups (diatoms, dinoflagellates, and coccolithophores), zooplankton, nutrients
$\left(\mathrm{NO}_{3}, \mathrm{PO}_{4}, \mathrm{NH}_{4}, \mathrm{SiO}_{2}\right.$, and $\left.\mathrm{Fe}\right), \mathrm{POC}$, DIC, DOC, alkalinity (TA), calcite production, chlorophyll, complete carbonate chemistry, and air-sea $\mathrm{CO}_{2}$ flux. The governing equations for the biogeochemical model are provided hereafter, where the subscripted index $i=1,2,3$ represents diatoms, dinoflagellates, and coccolithophores, respectively. Iron (Fe) limitation, although included in the model, was not considered in this study. However, there is evidence (Nielsdóttir et al., 2009) of iron limitation of the post-bloom (July to early September) phytoplankton communities in the Iceland Basin, east of the model location, where high nutrient-low chlorophyll (HNLC) conditions may occur. Iron limitation studies in the Iceland Basin will be a topic of future studies using the same model.

The basic form of the model equations for a generic tracer of concentration $C$, differentiated with respect to time $t$ and vertical coordinate $z$ and balanced by the sources and sinks of the particular biogeochemical property, is:

$$
\frac{\partial C}{\partial t}+w \frac{\partial C}{\partial z}-\frac{\partial}{\partial z}\left[k_{v} \frac{\partial C}{\partial z}\right]=\text { sources }- \text { sinks }
$$

where $w$ is the vertical velocity and $k_{v}$ is the vertical eddy diffusivity. We simplify the notation of the left hand side of all equations by substituting it with the single term $\frac{\mathrm{d} C}{\mathrm{~d} t}$.

\section{B1 Phytoplankton (diatoms, dinoflagellates, and coccolithophores)}

$$
\begin{aligned}
& \frac{\mathrm{d} P_{i}}{\mathrm{~d} t}=\mu_{i, \text { phy }} P_{i}-\mu_{i, \text { zoo }} Z-\left(R_{\text {phy,NO }}+M_{\text {phy,det }}\right) \\
& \left(P_{i}-P_{i . o}\right)-w_{P_{i}} \frac{\partial P_{i}}{\partial z}
\end{aligned}
$$

\section{B2 Zooplankton}

$$
\frac{\mathrm{d} Z}{\mathrm{~d} t}=\gamma \sum_{i}\left(\mu_{i, \mathrm{zoo}} Z\right)-E_{\mathrm{zoo}, \mathrm{NO}_{3}}\left(Z-Z_{o}\right)-M_{\mathrm{zoo}, \mathrm{det}}\left(Z-Z_{o}\right)^{2}
$$

\section{B3 Nutrients}

$$
\begin{aligned}
& \frac{\mathrm{dNO}_{3}}{\mathrm{~d} t}-\frac{1}{\tau}\left(\mathrm{NO}_{3} *-\mathrm{NO}_{3}\right) \\
& =-\pi_{2} \sum_{i}\left(\mu_{i, \text { phy }} P_{i}\right)+A_{n}\left(\frac{\mathrm{NH}_{4}}{0.07+\mathrm{NH}_{4}}\right)
\end{aligned}
$$

$$
\begin{aligned}
& \frac{\mathrm{dNH}_{4}}{\mathrm{~d} t}=a_{p} M_{\mathrm{phy}, \mathrm{det}} \sum_{i}\left(P_{i}-P_{i, o}\right)+R_{\mathrm{phy}, \mathrm{NO}_{3}} \\
& \sum_{i}\left(P_{i}-P_{i, o}\right)-\pi_{1} \sum_{i}\left(\mu_{i, \text { phy }} P_{i}\right)+\operatorname{remdet}_{N}+a_{z} M_{\text {zoo,det }} Z^{2} \\
& +E_{\mathrm{zoo}, \mathrm{NO}_{3}}\left(Z-Z_{o}\right)-A_{n}\left(\frac{\mathrm{NH}_{4}}{0.07+\mathrm{NH}_{4}}\right)+k_{\mathrm{rn}} \mathrm{DON}
\end{aligned}
$$


Table B1. Ecosystem/carbon model state variables definition, forcing strategy, and initial values.

\begin{tabular}{|c|c|c|c|}
\hline Symbol & Units & Parameter & Forcing/Initial value \\
\hline $\mathrm{NO}_{3}$ & $\mathrm{mmol} \mathrm{N} \mathrm{m}^{-3}$ & Dissolved inorganic nitrate & $* *$ Deep water NR \\
\hline $\mathrm{PO}_{4}$ & $\mathrm{mmol} \mathrm{P} \mathrm{m}{ }^{-3}$ & Dissolved inorganic phosphorus & $* *$ Deep water NR \\
\hline $\mathrm{SiO}_{2}$ & $\mathrm{mmol} \mathrm{Si} \mathrm{m}^{-3}$ & Dissolved inorganic silica & $* *$ Deep water NR \\
\hline $\mathrm{NH}_{4}$ & $\mathrm{mmol} \mathrm{N} \mathrm{m}^{-3}$ & Ammonium & 0.05 \\
\hline $\mathrm{O}_{2}$ & $\mu \mathrm{mol} \mathrm{kg}^{-1}$ & Dissolved oxygen & 268.0 \\
\hline $\mathrm{CaCO}_{3}$ & $\mathrm{mmol} \mathrm{C} \mathrm{m}{ }^{-3}$ & Calcium carbonate (calcite) & 0.01 \\
\hline DIC & $\mu \mathrm{mol} \mathrm{kg}^{-1}$ & Dissolved inorganic carbon & **Deep water $\mathrm{NR}+$ trend \\
\hline TA & $\mu \mathrm{mol} \mathrm{kg}-1$ & Alkalinity & **Deep water NR \\
\hline $\mathrm{P}_{i}$ & $\mathrm{mmol} \mathrm{N} \mathrm{m}{ }^{-3}$ & Phytoplankton $(i=1,2,3)^{*}$ & 0.1 \\
\hline $\mathrm{Pi}, \mathrm{o}$ & $\mathrm{mmol} \mathrm{N} \mathrm{m}^{-3}$ & $P$ background concentration & 0.001 \\
\hline $\mathrm{Z}$ & $\mathrm{mmol} \mathrm{N} \mathrm{m}^{-3}$ & Zooplankton & 0.1 \\
\hline Zo & $\mathrm{mmol} \mathrm{N} \mathrm{m}^{-3}$ & $Z$ background concentration & 0.001 \\
\hline DON & $\mathrm{mmol} \mathrm{N} \mathrm{m}^{-3}$ & Dissolved organic nitrogen & $1.0 / 0.0$ \\
\hline DOP & $\mathrm{mmol} \mathrm{P} \mathrm{m}^{-3}$ & Dissolved organic phosphorus & $0.06 / 0.0$ \\
\hline DOC & $\mu \mathrm{mol} \mathrm{C} \mathrm{kg}{ }^{-1}$ & Labile dissolved organic carbon & $15.0 / 0.0$ \\
\hline $\operatorname{det}_{N}$ & $\mathrm{mmol} \mathrm{N} \mathrm{m}^{-3}$ & Detrital particulate nitrogen & 0.001 \\
\hline $\operatorname{det}_{P}$ & $\mathrm{mmol} \mathrm{P} \mathrm{m}{ }^{-3}$ & Detrital particulate phosphate & 0.001 \\
\hline $\operatorname{det}_{S}$ & mmol Si m ${ }^{-3}$ & Detrital particulate silicate & 0.001 \\
\hline $\operatorname{det}_{\mathrm{PCaCO} 3}$ & $\mathrm{mmol} \mathrm{CaCO} \mathrm{m}^{-3}$ & Detrital particulate calcite & 0.001 \\
\hline
\end{tabular}

*Diatoms $(i=1)$, dinoflagellates $(i=2)$, and coccolithophores $(i=3) * *$ Deep layer Newtonian relaxation to values in (B40), (B41), and (B42).

$$
\begin{aligned}
& \frac{\mathrm{dPO}_{4}}{\mathrm{~d} t}-\frac{1}{\tau}\left(\mathrm{PO}_{4} *-\mathrm{PO}_{4}\right)=k_{\mathrm{rp}} \mathrm{DOP}+\operatorname{rem}_{\operatorname{det}} P \\
& +\left[\left(a_{p} M_{\mathrm{phy}, \mathrm{det}}+R_{\mathrm{phy}_{\mathrm{N} O}}\right) \sum_{i}\left(P_{i}-P_{i, o}\right)\right. \\
& \left.-\sum_{i}\left(\mu_{i, \text { phy }} P_{i}\right)+a_{z} M_{\mathrm{zoo}, d e t} Z^{2}+E_{\mathrm{zoo}, \mathrm{NO}_{3}}\left(Z-Z_{o}\right)\right] \frac{1}{r_{1}} \\
& \frac{\mathrm{dSiO}_{2}}{\mathrm{~d} t}-\frac{1}{\tau}\left(\mathrm{SiO}_{2}^{*}-\mathrm{SiO}_{2}\right) \\
& =\left[\left(a_{p} M_{\mathrm{phy}, \mathrm{det}}+R_{\mathrm{phy}, \mathrm{NO}_{3}}\right)\left(P_{1}-P_{1, o}\right)\right. \\
& -\sum_{i}\left(\mu_{2, \text { phy }} P_{2}\right)\left[+a_{z} M_{\mathrm{zoo}, \operatorname{det}} Z^{2}+E_{\mathrm{zoo}, \mathrm{NO}_{3}}\left(Z-Z_{o}\right)\right]\left(\frac{\mathrm{S}}{\mathrm{N}}\right)_{\mathrm{Red}} \\
& +k_{\mathrm{rp}} \mathrm{DOS}+\text { rem det } \mathrm{S}
\end{aligned}
$$

\section{B4 Dissolved organic matter}

$$
\begin{aligned}
& \frac{\mathrm{dDON}}{\mathrm{d} t}=a_{p}^{\prime} M_{\mathrm{phy}, \mathrm{det}} \sum_{i}\left(P_{i}-P_{i, o}\right)+a_{Z}^{\prime} M_{\mathrm{zoo}, \mathrm{det}} Z^{2}-k_{\mathrm{rn}} \mathrm{DON} \\
& \frac{\mathrm{dDOP}}{\mathrm{d} t}=\frac{1}{r_{1}}\left[a_{p}^{\prime} M_{\mathrm{phy}, \mathrm{det}} \sum_{i}\left(P_{i}-P_{i, o}\right)+a_{Z}^{\prime} M_{\mathrm{zoo}, \mathrm{det}} Z^{2}\right]-k_{\mathrm{rp}} \mathrm{DOP} \\
& \frac{\mathrm{dDOC}}{\mathrm{d} t}=\frac{1}{\rho}\left[0.15 \sum_{i}\left(\mu_{i, p h y} P_{i}\right)+a_{p}^{\prime} M_{\mathrm{phy}, \mathrm{det}} \sum_{i}\left(P_{i}-P_{i, o}\right)+a_{Z}^{\prime} M_{\mathrm{zoo}, \mathrm{det}} Z^{2}\right] \\
& \left(\frac{\mathrm{C}}{\mathrm{N}}\right)_{\text {Red }}-k_{\mathrm{rc}} \mathrm{DOC}
\end{aligned}
$$

\section{B5 Detritus}

$\frac{\mathrm{ddet}_{\mathrm{N}}}{\mathrm{dt}}=\left(1-a_{p}-a_{p}^{\prime}\right)\left[M_{\mathrm{phy}, \mathrm{det}} \sum_{i}\left(P_{i}-P_{i, o}^{)}\right]+(1-\gamma) \sum_{i}\left(\mu_{i, \mathrm{zoo}}^{Z}\right)\right.$
$+\left(1-a_{z}-a_{z}^{\prime}\right) M_{\mathrm{zoo}, \operatorname{det}} Z^{2}-w_{\operatorname{det}} \frac{\partial \operatorname{det}_{\mathrm{N}}}{\partial \mathrm{z}}-\operatorname{rem}_{\operatorname{det}_{\mathrm{N}}}$

$\frac{\mathrm{ddetp}}{\mathrm{dt}}=\left(1-a_{p}-a_{p}^{\prime}\right)\left[M_{\mathrm{phy}, \operatorname{det}} \sum_{i}\left(P_{i}-P_{i, o}\right) \frac{1}{r_{1}}\right]$

$+\left[(1-\gamma) \sum_{i}\left(\mu_{i, \mathrm{zoo}} Z\right)+\left(1-a_{z}-a_{z}^{\prime}\right) M_{\mathrm{zoo}, \operatorname{det}} Z^{2}\right] \frac{1}{r_{1}}$

$-w_{\operatorname{det}} \frac{\partial \operatorname{det}_{\mathrm{P}}}{\partial \mathrm{z}}-\operatorname{rem} \operatorname{det}_{\mathrm{P}}$

$\frac{\mathrm{ddet}_{\mathrm{s}}}{\mathrm{dt}}=\left[\left(1-a_{p}-a_{p}^{\prime}\right) M_{\mathrm{phy}, \operatorname{det}}\left(P_{1}-P_{1, o}\right)\right.$

$\left.+(1-\gamma)\left(\mu_{2, \mathrm{zoo}} Z\right)+\left(1-a_{z}-a_{z}^{\prime}\right) M_{\mathrm{zoo}, \operatorname{det}} Z^{2}\right]$

$\left(\frac{\mathrm{S}}{\mathrm{N}}\right)_{\text {Red }}-w_{\operatorname{det}} \frac{\partial \operatorname{det}_{\mathrm{S}}}{\partial \mathrm{z}}-\mathrm{rem}_{\mathrm{det}}$

$\frac{\mathrm{ddet}_{\mathrm{CaCO}_{3}}}{\mathrm{dt}}=\left(\frac{\mathrm{C}}{\mathrm{N}}\right)_{\mathrm{Coc}}\left[\left(1-a_{p}-a_{p}^{\prime}\right) M_{\mathrm{phy}}, \operatorname{det}\left(P_{3}-P_{3, o}\right)\right.$

$\left.+(1-\gamma)\left(\mu_{3, \mathrm{zoo}} Z\right)+\left(1-a_{z}-a_{z}^{\prime}\right) M_{\mathrm{zoo}, \mathrm{det}} Z^{2}\right]$

$-w_{\operatorname{det}} \frac{\partial \operatorname{det}_{\mathrm{CaCO}_{3}}}{\partial \mathrm{z}}$

B6 Calcite

$\frac{\mathrm{dCaCO}}{\mathrm{d} t}=P_{\mathrm{CaCO}_{3}}-\lambda_{\mathrm{CaCO}_{3}}^{*} \mathrm{CaCO}_{3}-w_{\mathrm{det}} \frac{\partial \mathrm{CaCO}_{3}}{\partial \mathrm{z}}$ 
Table B2. Summary of ECO1D-2.0 parameters used in the 1981-2008 simulation for the subpolar North Atlantic. Equivalent parameters used in ECO1D-1.0 for the BATS site are included in parenthesis where appropriate (ECO1D-1.0 combines all phytoplankton into one single group, so phytoplankton-relevant parameters are provided under the diatoms group in this table).

\begin{tabular}{|c|c|c|c|}
\hline $\begin{array}{l}\text { Parameter } \\
\text { Diatoms }\left(P_{1}\right)\end{array}$ & Symbol & Units & Value \\
\hline Maximum growth rate & $\mu_{\text {phy,max }}$ & day $^{-1}$ & $1.2(3.0)$ \\
\hline Initial P-I slope & $\alpha_{1}$ & $\left(\mathrm{~W} \mathrm{~m}^{-2}\right)^{-1} \mathrm{day}^{-1}$ & $0.09(0.25)$ \\
\hline Nitrate half saturation constant & $k_{\mathrm{NO} 3}$ & $\mathrm{mmol} \mathrm{N} \mathrm{m}^{-3}$ & $2.0(0.025)$ \\
\hline Phosphate half saturation constant & $k_{\mathrm{PO} 4}$ & $\mathrm{mmol} \mathrm{P} \mathrm{m}{ }^{-3}$ & $0.0015(0.0025)$ \\
\hline Silicate half saturation constant & $k_{\mathrm{SiO} 2}$ & mmol Si m ${ }^{-3}$ & 0.3 \\
\hline Ammonium half saturation (all functional types) & $k_{\mathrm{NH} 4}$ & $\mathrm{mmol} \mathrm{N} \mathrm{m}{ }^{-3}$ & $0.5(0.025)$ \\
\hline Respiration rate & $\mathrm{R}_{\text {phy,NO3 }}$ & day $^{-1}$ & $0.05(0.05)$ \\
\hline Mortality rate & $M_{\text {phy,det }}$ & day $^{-1}$ & $0.05(0.05)$ \\
\hline Maximum sinking speed & $w_{P}$ & $m$ day $^{-1}$ & 1.0 \\
\hline \multicolumn{4}{|l|}{ Dinoflagellates $\left(P_{2}\right)$} \\
\hline Maximum growth rate & $\mu_{\text {phy,max }}$ & day $^{-1}$ & 0.65 \\
\hline Initial P-I slope & $\alpha_{1}$ & $\left(\mathrm{~W} \mathrm{~m}^{-2}\right)^{-1}$ day $^{-1}$ & 0.10 \\
\hline Nitrate half saturation constant & $k_{\mathrm{NO} 3}$ & $\mathrm{mmol} \mathrm{N} \mathrm{m}^{-3}$ & 0.67 \\
\hline Phosphate half saturation constant & $k_{\mathrm{PO} 4}$ & $\mathrm{mmol} \mathrm{P} \mathrm{m}{ }^{-3}$ & 0.0015 \\
\hline Respiration rate & $R_{\text {phy,NO3 }}$ & day $^{-1}$ & 0.05 \\
\hline Mortality rate & $M_{\text {phy,det }}$ & day $^{-1}$ & 0.05 \\
\hline \multicolumn{4}{|l|}{ Coccolithophores $\left(P_{3}\right)$} \\
\hline Maximum growth rate & $\mu_{\text {phy,max }}$ & day $^{-1}$ & 1.15 \\
\hline Initial P-I slope & $\alpha_{1}$ & $\left(\mathrm{~W} \mathrm{~m}{ }^{-2}\right)^{-1}$ day $^{-1}$ & 0.033 \\
\hline Nitrate half saturation constant & $k_{\mathrm{NO} 3}$ & $\mathrm{mmol} \mathrm{N} \mathrm{m}^{-3}$ & 1.0 \\
\hline Phosphate half saturation constant & $k_{\mathrm{PO} 4}$ & $\mathrm{mmol} \mathrm{P} \mathrm{m}^{-3}$ & 0.0015 \\
\hline Respiration rate & $R_{\text {phy,NO3 }}$ & day $^{-1}$ & 0.05 \\
\hline Mortality rate & $M_{\text {phy,det }}$ & day $^{-1}$ & 0.05 \\
\hline Maximum sinking speed & $w_{P}$ & $m$ day $^{-1}$ & 5.0 \\
\hline \multicolumn{4}{|l|}{ Zooplankton (Z) } \\
\hline Maximum grazing rate & $\mu_{\mathrm{zoo}, \max }$ & day $^{-1}$ & $1.2(1.0)$ \\
\hline Ingestion half saturation constant & $k_{\text {phy }}$ & $\left(\mathrm{mmol} \mathrm{N} \mathrm{m}{ }^{-3}\right)^{-2}$ & $0.25(0.25)$ \\
\hline Assimilation efficiency & $\gamma$ & & $0.75(0.75)$ \\
\hline Excretion rate & $E_{\mathrm{Zoo}, \mathrm{NO} 3}$ & day $^{-1}$ & $0.1(0.05)$ \\
\hline Mortality rate & $M_{\text {zoo,det }}$ & day $^{-1}\left(\mathrm{mmol} \mathrm{N} \mathrm{m}^{-3}\right)^{-1}$ & $0.1(0.05)$ \\
\hline \multicolumn{4}{|c|}{ Dissolved organic matter (DOM), detritus (det), and remineralization } \\
\hline Remineralization rate of detritus & rem & day $^{-1}$ & $0.01(0.001)$ \\
\hline Remineralization rate of DON & $k_{\mathrm{rn}}$ & day $^{-1}$ & $0.00001(0.00001)$ \\
\hline Remineralization rate of DOP & $k_{\mathrm{rp}}$ & day $^{-1}$ & $0.00001(0.00001)$ \\
\hline Remineralization rate of DOSi & $k_{r s}$ & day $^{-1}$ & 0.00001 \\
\hline Remineralization rate of DOC & $k_{\mathrm{rc}}$ & day $^{-1}$ & $0.0005(0.0005)$ \\
\hline Fraction of dead phytoplankton converted to $\mathrm{NH}_{4}$ & $a_{p}$ & & $0.8(0.8)$ \\
\hline Fraction of dead zooplankton converted to $\mathrm{NH}_{4}$ & $a_{z}$ & & $0.8(0.8)$ \\
\hline Fraction of dead phytoplankton converted to DOM & $a_{p}^{\prime}$ & & $0.1(0.1)$ \\
\hline Fraction of dead zooplankton converted to DOM & $a_{z}^{\prime}$ & & $0.1(0.1)$ \\
\hline Maximum sinking speed & $w_{\text {det }}$ & $\mathrm{m}_{\text {day }}{ }^{-1}$ & $1.0(2.5)$ \\
\hline \multicolumn{4}{|l|}{ Ammonium $\left(\mathrm{NH}_{4}\right)$ nitrification } \\
\hline Maximum rate of ammonium nitrification & $A_{n, \max }$ & $\mu \mathrm{mol} \mathrm{m}^{-3}$ day $^{-1}$ & $0.02(0.02)$ \\
\hline Minimum light inhibition dosage for nitrification & $D_{\min }$ & $\mathrm{W} \mathrm{m}^{-2}$ & $0.0095(0.0095)$ \\
\hline Half saturation dosage for nitrification photoinhibition & $K_{D}$ & $\mathrm{~W} \mathrm{~m}^{-2}$ & $0.036(0.8)$ \\
\hline \multicolumn{4}{|l|}{ Calcite $\left(\mathrm{CaCO}_{3}\right)$} \\
\hline Maximum calcification to organic carbon production & $R_{\mathrm{CaCO} 3}$ & & 0.4 \\
\hline Calcite dissolution rate & $\gamma_{\mathrm{CaCO} 3}$ & day $^{-1}$ & 0.03 \\
\hline \multicolumn{4}{|l|}{ Chlorophyll $a(\mathrm{Chl} a)$} \\
\hline Minimum chlorophyll to nitrogen ratio & Chl: $\mathrm{N}^{\min }$ & $\mathrm{mg} \mathrm{Chl}(\mathrm{mmol} \mathrm{N})^{-1}$ & $1.5(0.8)$ \\
\hline Maximum chlorophyll to nitrogen ratio & Chl:N $\mathrm{N}^{\max }$ & $\operatorname{mg~Chl~}(\operatorname{mmol~N})^{-1}$ & $3.5(1.6)$ \\
\hline Critical irradiance for photoadaptation & $I *$ & $\mathrm{~W} \mathrm{~m}^{-2}$ & 25.0 \\
\hline
\end{tabular}




\section{B7 Dissolved inorganic carbon}

$$
\begin{aligned}
& \frac{\mathrm{dDIC}}{\mathrm{d} t}-\frac{1}{\tau}\left(\mathrm{DIC}^{*}-\mathrm{DIC}\right)=\delta(z) \frac{\mathrm{FCO}_{2}}{\rho}-\frac{N_{P}}{\rho}+\frac{1}{S_{o}} \frac{\partial S}{\partial t} \mathrm{DIC} \\
& +\frac{1}{\rho}\left[\lambda_{\mathrm{CaCO}_{3}}^{*} \mathrm{CaCO}_{3}-P_{\mathrm{CaCO}_{3}}\right]
\end{aligned}
$$

\section{B8 Alkalinity}

$$
\begin{aligned}
& \frac{\mathrm{dTA}}{\mathrm{d} t}-\frac{1}{\tau}\left(\mathrm{TA}^{*}-\mathrm{TA}\right)=\frac{N_{P}}{\rho}+\frac{1}{S_{o}} \frac{\partial S}{\partial t} T A \\
& +\frac{2}{\rho}\left[\lambda_{\mathrm{CaCO}_{3}}^{*} \mathrm{CaCO}_{3}-P_{\mathrm{CaCO}_{3}}\right]
\end{aligned}
$$

B9 Calcite production, calcification/organic carbon production ratio $\left(\boldsymbol{R}_{\mathrm{CaCO3}}\right)$ and calcite dissolution rate $\left(\lambda_{\mathrm{CaCO3}}\right)$

$$
\begin{aligned}
& \left.P_{\mathrm{CaCO}_{3}}=R_{\mathrm{CaCO}_{3}}^{*}\left[\frac{\mathrm{C}}{\mathrm{N}}\right]_{\mathrm{Coc}}\left(Z-Z_{o}\right)-M_{\text {phy,det }}\left(P_{3}-P_{3, o}\right)\right] \\
& {\left[\left(\mu_{3, \text { phyto }} P_{3}-0.5 E_{\mathrm{zoo}, \mathrm{NO}_{3}}(Z)\right.\right.} \\
& R_{\mathrm{CaCO}_{3}}^{*}=R_{\mathrm{CaCO}_{3}} F_{3, \text { phy }}(E) \min \\
& {\left[\mathrm{N}_{\mathrm{lim}}, \frac{\mathrm{PO}_{4}}{k_{\mathrm{P} 1}+\mathrm{PO}_{4}}\right] \max \left[0.0001, \frac{T}{2+T}\right] \max \left[1, \frac{P_{3}}{2}\right]} \\
& \lambda_{\mathrm{CaCO}_{3}}^{*}=\lambda_{\mathrm{CaCO}_{3}} \frac{\Delta \mathrm{CO}_{3}}{k_{\mathrm{CaCO}^{3}+\Delta \mathrm{CO}_{3}}} \\
& \Delta \mathrm{CO}_{3}=\max \left(0, \mathrm{CO}_{\mathrm{sat}}^{2-}-\mathrm{CO}^{2-}\right)
\end{aligned}
$$

\section{B10 Net community production}

$$
\begin{aligned}
& N_{p}=\left(\frac{\mathrm{C}}{\mathrm{N}}\right)_{\mathrm{Red}}\left[\mu_{1, \mathrm{phy}} P_{1}+\mu_{2, \mathrm{phy}} P_{2}-\left(a_{p} M_{\mathrm{phy}, \mathrm{det}}+R_{\mathrm{phy}, \mathrm{NO}}\right)\right. \\
& \left\{\left(P_{1}-P_{1, o}\right)+\left(P_{2}-P_{2,0}\right)\right\}-a_{Z} M_{\mathrm{zoo}, \mathrm{det}} Z^{2} \\
& \left.-R_{\mathrm{zoo}, \mathrm{NO}_{3}}\left(Z-Z_{o}\right)-\operatorname{rem} \operatorname{det}_{\mathrm{N}}\right]-k_{\mathrm{rc}} \mathrm{DOC}+\left(\frac{\mathrm{C}}{\mathrm{N}}\right)_{\mathrm{Coc}} \mu_{3, \mathrm{phy}} P
\end{aligned}
$$

\section{B11 Oxygen}

$$
\frac{\mathrm{dO}_{2}}{\mathrm{~d} t}=\delta(z) \frac{\mathrm{FO}_{2}}{\rho}+\frac{N_{P}}{\rho}\left(\frac{\mathrm{O}_{2}}{\mathrm{~N}}\right)_{\text {Red }}
$$

\section{B12 Nutrient limitation}

$$
\begin{aligned}
& \mathrm{N}_{\lim }=\mathrm{NH}_{4 \lim }+\mathrm{NO}_{3 \lim } \\
& \mathrm{NO}_{\lim }=\frac{\mathrm{NO}_{3}}{\left(K_{\mathrm{NO}_{3}}+\mathrm{NO}_{3}\right)} \frac{\left(1-\mathrm{NH}_{4}\right)}{\left(K_{\mathrm{NH}_{4}}+\mathrm{NH}_{4}\right)} \\
& \mathrm{NH}_{\lim }=\frac{\mathrm{NH}_{4}}{\left(K_{\mathrm{NH}_{4}}+\mathrm{NH}_{4}\right)} \\
& \pi_{1}=\frac{\mathrm{NH}_{4 \lim }}{\mathrm{NH}_{4 l i m}+\mathrm{NO}_{3 \lim }} \\
& \pi_{2}=\frac{\mathrm{NO}_{3 \lim }}{\mathrm{NH}_{4 l i m}+\mathrm{NO}_{3 \lim }}
\end{aligned}
$$

\section{B13 Irradiance model}

The total (infrared plus visible) solar radiation is obtained using the Frouin model (Frouin et al., 1989). This model provides the total radiation and the photosynthetically available radiation $(\mathrm{PAR})$. The infrared $\left(I_{\mathrm{IR}}\right)$ component is obtained by subtracting the PAR component from the total solar radiation. Using a spectral model for PAR (Gregg and Carder, 1990), the spectral PAR component $I_{\mathrm{PAR}}(\lambda)$ can be determined. The infrared component (for mixed layer model only) and the PAR component (mixed layer and biogeochemical model) of the penetrating irradiance are obtained from

$I_{\mathrm{IR}}(z)=I_{\mathrm{IR}}(z-\Delta z) \exp \left[-a_{\mathrm{IR}} \Delta z\right]$

$I_{\mathrm{PAR}}(\lambda, z)=I(\lambda, z-\Delta z) \exp \left[-\left(a_{w}(\lambda)+a_{\mathrm{ph}}(\lambda)\right) \Delta z\right]$

where $a_{\mathrm{IR}}\left(3.75 \mathrm{~m}^{-1}\right)$ is the attenuation coefficient for infrared radiation and $a_{w}(\lambda)$ and $a_{\mathrm{ph}}(\lambda)$ are the wavelengthdependent light attenuation coefficients for water and phytoplankton, respectively. The water and chlorophyll-dependent attenuation coefficients from Morel (1988) were used in the model for this study. The dissolved matter attenuation coefficients, $a_{\mathrm{dm}}(\lambda)$, are calculated by applying the IOP (inherent optical properties) model of Garver and Siegel (1997), which uses water leaving radiances from 6 SeaWiFS bands as input (level 3 binned monthly composites). The IOP model calculates the attenuation coefficient due to dissolved matter for the $443 \mathrm{~nm}$ wavelength. The attenuation coefficients for other wavelengths are obtained from

$a_{\mathrm{dm}}(\lambda)=a_{\mathrm{dm}}(443) \exp [S(\lambda-443)]$

where the exponential decay constant, $S$, is chosen to be 0.02061 . A correction is applied to the downward irradiance pathway to account for seawater light refraction following Snell's law. After some algebraic manipulations, the correction is applied to $\Delta z$ as follows:

$\Delta z^{\prime}=\frac{\Delta z}{\cos \beta}$

$\beta=a \sin \left[\frac{\alpha_{z}}{n_{s}}\right]$

where $\alpha_{z}$ is the solar zenith angle, and $n_{s}$ is the seawater refraction coefficient, which is expressed as a function of salinity and temperature adapted from Table 3.12 of Neumann and Pierson (1966) as

$n_{s}=10^{-6}(285.77-15.65 T+197.67 S)+1.333338 \quad(\mathrm{~B} 30)$ 


\section{B13.1 Ammonium nitrification}

$$
\begin{aligned}
& A_{n}=A_{n}^{\max }\left(1-\frac{D-D_{\min }}{D-D_{\min }-K_{D}}\right) \\
& D=\int_{t=0}^{t=24 \lambda=470} \int_{\lambda=300} I(\lambda, t) \alpha_{S}(\lambda) d \lambda d t
\end{aligned}
$$

\section{B14 Phytoplankton growth}

$$
\begin{aligned}
& \mu_{i, \text { phy }}\left(\mathrm{NO}_{3}, \mathrm{PO}_{4}, \mathrm{SiO}_{2}, E\right)=F_{i, \text { phy }}(E) \\
& \times \min \left[\mathrm{N}_{\text {lim }}, \frac{\mathrm{PO}_{4}}{k_{\mathrm{PO}_{4}}+\mathrm{PO}_{4}}, \frac{\mathrm{SiO}_{2}}{k_{\mathrm{SiO}_{2}}+\mathrm{SiO}_{2}}\right] \\
& F_{i, \text { phy }}(I)=\frac{\mu_{i, \text { phy }}^{\max } \alpha_{i} I}{\sqrt{\left(\mu_{i, \text { phy }}^{\text {max }}\right)^{2}+\left(\alpha_{i} I\right)^{2}}}
\end{aligned}
$$

Note: $\mathrm{SiO}_{2}$ included for diatoms only. $r_{1}=14$ is $\mathrm{N}: \mathrm{P}$.

\section{B15 Zooplankton grazing}

$\mu_{\mathrm{zoo}}\left(P_{i}\right)=\mu_{\mathrm{zoo}}^{\max } \frac{P_{i}^{2}}{k_{\mathrm{phy}}+P_{i}^{2}}$

\section{B16 Primary production}

$$
\begin{aligned}
& \mathrm{PP}=\left[\left(\mu_{1, \text { phy }} P_{1}+\mu_{2, \text { phy }} P_{2}\right)\left(\frac{\mathrm{C}}{\mathrm{N}}\right)_{\text {Red }}+\mu_{3, \text { phy }} P_{3}\left(\frac{\mathrm{C}}{\mathrm{N}}\right)_{\mathrm{Coc}}\right] \mathrm{C}_{\mathrm{MW}} \\
& \left(\frac{\mathrm{C}}{\mathrm{N}}\right)_{\text {Red }}=6.625 \quad\left(\frac{\mathrm{C}}{\mathrm{N}}\right)_{\mathrm{Coc}}=9.4 \quad \mathrm{C}_{\mathrm{MW}}=12 \\
& \left(\frac{\mathrm{Si}}{\mathrm{N}}\right)_{\text {Red }}=\frac{15}{16}
\end{aligned}
$$

The C:N ratio for coccolithophores (Coc) of 9.4 is the average from the reported range of 5.81 to 13.05 in Fernandez et al. (1993).

\section{B17 Chlorophyll and Chl:N ratio}

The model chlorophyll is calculated following the photoadaptation scheme for Chl:N ratio of Doney et al. (1996):

Chl $a=\mathrm{Chl:N} \sum_{\mathrm{i}} P_{i}$

Chl:N=Chl: $\mathrm{N}^{\max }-\left(\mathrm{Chl}: \mathrm{N}^{\mathrm{max}}-\mathrm{Chl}: \mathrm{N}^{\mathrm{min}}\right) \frac{I_{\mathrm{PAR}}}{I_{*}} \quad I_{\mathrm{PAR}}<I_{*}$ $\mathrm{Chl}: \mathrm{N}=\mathrm{Chl}: \mathrm{N}^{\mathrm{min}} \quad I_{\mathrm{PAR}} \geq I_{*}$

The subscripts phy, zoo, and det refer to phytoplankton, zooplankton, and detritus, respectively. Table B1 defines the model state variables and Table B2 provides the definition of the ECO1D-2.0 parameters and values used. Equivalent parameters for ECO1D-1.0, configured for and applied at the BATS site, are shown in parenthesis for comparison.

\section{B18 Model forcing and relaxation approach}

The terms $\delta(\mathrm{z}) \mathrm{FCO}_{2} / \rho$ and $\delta(\mathrm{z}) \mathrm{FO}_{2} / \rho$, in (B15) and (B19), respectively, represent the $\mathrm{CO}_{2}$ and $\mathrm{O}_{2}$ sea-air fluxes at the surface. The Kroenecker delta $(\delta[z=0]=1 ; \delta[z>0]=0)$ is used to denote that carbon dioxide and oxygen fluxes $\left(\mathrm{FCO}_{2}\right.$ and $\mathrm{FO}_{2}$, respectively) are only applied at the sea-air interface. The following formulations for the $\mathrm{CO}_{2}$ and $\mathrm{O}_{2}$ gas transfer were applied in the form of flux boundary conditions $\left(\mathrm{FCO}_{2}\right.$ and $\mathrm{FO}_{2}$ in $\mathrm{mmol} \mathrm{m}^{-2} \mathrm{yr}^{-1}$ ) at the sea-air interface:

$\mathrm{FCO}_{2}=K_{o} \alpha \Delta p \mathrm{CO}_{2} \mathrm{FO}_{2}=K_{o}\left[\mathrm{O}_{2}^{*}-\mathrm{O}_{2}\right]$

where, $K_{o}$ is the gas transfer velocity, in $\mathrm{m} \mathrm{d}^{-1}$, which is a function of water temperature and wind speed (Wanninkhof, 1992), $\alpha$ is the $\mathrm{CO}_{2}$ solubility in seawater (in mmol $\mathrm{m}^{-3} \mu \mathrm{atm}$ ), which is a function of temperature and salinity (Weiss, 1974), $\Delta p \mathrm{CO}_{2}$ (in $\mu \mathrm{atm}$ ) is the difference between sea and air $p \mathrm{CO}_{2}$, and $\mathrm{O}_{2}^{*}$ is the oxygen saturation concentration (in $\mathrm{mmol} \mathrm{m}{ }^{-3}$ ) in seawater, which is a function of temperature and atmospheric pressure (Weiss, 1970).

We adopt the following relationship between gas transfer and wind speed $(W)$ (Wanninkhof, 1992) using the NCEP 3 hourly winds:

$K_{o}=0.31 W^{2}(\mathrm{Sc} / 660)^{-1 / 2}$

where $\mathrm{Sc}$ is the Schmidt number of $\mathrm{CO}_{2}$ or $\mathrm{O}_{2}$ (Wanninkhof, 1992).

To account for horizontal advective processes of heat and salt within deeper layers of the 1-D mixed layer model, temperature and salinity are assimilated from the 3-D model using a straightforward approach. The approach consists of relaxing the temperature and salinity profiles calculated by the 1-D mixed layer model to the pre-calculated values provided by the 3-D model at all depths. The assimilation of $T$ and $S$ is done using a Newtonian relaxation (nudging) method (Bauer and Wulfmeyer, 2009) with a relaxation time scale $(\tau)$ of 10 days for $T$ and 30 days for $S$. For model properties where the relaxation time scales for deep water are short (10 days or less), the term "nudging" is not applicable, as the properties are set to observed values.

A similar relaxation approach is used for nitrate, phosphate, and silicate, except that the nutrient values originate from $T$-dependent equations obtained from $T, \mathrm{NO}_{3}, \mathrm{PO}_{4}$, and $\mathrm{SiO}_{2}$ climatologic monthly profiles $(0-500 \mathrm{~m})$ from the World Ocean Atlas 2005 at the model site. The total number of data points is 168 ( $N=14$ depths $\times 12$ months). The equations are

$$
\begin{aligned}
\mathrm{NO}_{3}^{*} & =-2.253( \pm 0.169) T+29.92( \pm 1.21) \\
r^{2} & =0.814 \quad \text { RMSE }=1.258 \\
\mathrm{PO}_{4}^{*} & =-0.1333( \pm 0.0095) T+1.884( \pm 0.068) \\
r^{2} & =0.836 \quad \text { RMSE }=0.0707 \\
\mathrm{SiO}_{2}^{*} & =-1.479( \pm 0.135) T+17.37( \pm 0.98) \\
r^{2} & =0.735 \quad \text { RMSE }=1.012
\end{aligned}
$$




$$
\begin{aligned}
& \mathrm{DIC}^{*}=n C_{T} \times S / 35 \\
& n C_{T}=1962.6-14.6204(T-20)-0.1371(T-20)^{2} \\
& r^{2}=0.762, \mathrm{RMSE}=10.15, N=148 \\
& \mathrm{TA}^{*}=2311.6+46.4153(S-35)+56.4425(S-35)^{2} \\
& -0.0456(T-20)-0.0387(T-20)^{2} \\
& r^{2}=0.448, \mathrm{RMSE}=4.15, N=123
\end{aligned}
$$

Acknowledgements. This project was supported by the NASA Ocean Biology and Biogeochemistry Program. We want to acknowledge the project A-CARB of the Research Council of Norway. We also want to acknowledge the SURATLANTE project, which is supported by the Institut National de Sciences de l'Univers (INSU) in France, and the MarProd program sponsored by the Natural Environment Research Council (UK). Continuous Plankton Recorder data were obtained from the Sir Alistair Hardy Foundation for Ocean Sciences. We would like to acknowledge the support of the Reykjavik Marine Research Institute (MRI) personnel (Sólveig Ólafsdóttir and Magnus Danielsen).

Edited by: R. Marsh

\section{References}

Bailey, D. A., Rhines, P. B., and Hakkinen, S.: Formation and pathways of North Atlantic deep water in a coupled ice-ocean model of the Arctic-North Atlantic Oceans, Clim. Dynam., 25, 497516, 2005.

Balch, W., Drapeau, D., Bowler, B., and Booth, E.: Prediction of pelagic calcification rates using satellite measurements, DeepSea Res. Pt. II, 54, 478-495, 2007.

Balch, W. M., Holligan, P. M., and Kilpatrick, K. A.: Calcification, photosynthesis and growth of the bloom-forming coccolithophore, Emiliania huxleyi, Cont. Shelf Res., 12, 1353-1374, 1992.

Barron, C. N. and Smedstad, L. F.: Global river inflow within the Navy Coastal Ocean Model, paper presented at Oceans 2002 MTS/IEEE Conference, 29-31 October 2002.

Bauer, H. S. and Wulfmeyer, V.: Validation of components of the water cycle in the ECHAM4 general circulation model based on the Newtonian relaxation technique: a case study of an intense winter cyclone, Meteorol. Atmos. Phys., 104, 135-162, 2009.

Behrenfeld, M. J., Boss, E., Siegel, D. A., and Shea, D. M.: Carbon-based ocean productivity and phytoplankton physiology from space, Global Biogeochem. Cy., 19, GB1006, doi:10.1029/2004GB002299, 2005.

Bennington, V., McKinley, G. A., Dutkiewicz, S., and Ullman, D.: What does chlorophyll variability tell us about export and air-sea $\mathrm{CO}_{2}$ flux variability in the North Atlantic?, Global Biogeochem. Cy., 23, GB3002, doi:10.1029/2008GB003241, 2009.

de Boisséson, E., Thierry, V., Mercier, H., and Caniaux, G.: Mixed layer heat budget in the Iceland Basin from Argo, J. Geophys. Res., 115, C10055, doi:10.1029/2010JC006283, 2010.

Boyd, P. W. and Trull, T. W.: Understanding the export of biogenic particles in oceanic waters: Is there consensus?, Progr. Oceanogr., 72, 276-312, 2007.
Boyd, P. W., Strzepek, R., Fu, F. X., and Hutchins, D. A.: Environmental control of open-ocean phytoplankton groups: Now and in the future, Limnol. Oceanogr., 55, 1353-1376, 2010.

Carton, J. A., Grodsky, S. A., and Liu, H.: Variability of the oceanic mixed layer, 1960-2004, J. Climate, 21, 1029-1047, 2008.

Chierici, M., Olsen, A., Johannessen, T., Trinanes, J., and Wanninkhof, R.: Algorithms to estimate the carbon dioxide uptake in the Northern North Atlantic using shipboard observations, satellite and ocean analysis data, Deep-Sea Res. Pt. II, 56, 630-639, 2009.

Corbiere, A., Metzl, N., Reverdin, G., Brunet, C., and Takahashi, A.: Interannual and decadal variability of the oceanic carbon sink in the North Atlantic subpolar gyre, Tellus B, 59, 168-178, 2007.

Doney, S. C., Glover, D. M., and Najjar, R. G.: A new coupled, one-dimensional biologicalphysical model for the upper ocean: applications to the JGOFS Bermuda Atlantic time-series study (BATS) site, Deep-Sea Res. Pt. II, 43, 591-624, 1996.

de Boyer Montégut, C., Madec, G., Fischer, A. S., Lazar, A, and Iudicone, D.: Mixed layer depth over the global ocean: An examination of profile-based climatology, J. Geophys. Res., 109, C12003, doi:10.1029/2004JC002378, 2004.

Ducklow, H. W. and Harris, R. P.: Introduction to the JGOFS North Atlantic Bloom Experiment - The Joint Global Flux Study NorthAtlantic Bloom Experiment, Deep-Sea Res. Pt. II, 40, 1-8, 1993.

Egge, J. K., and Aksnes, D. L.: Silicate as regulating nutrient in phytoplankton competition, Mar Ecol-Prog. Ser., 83, 281-289, 1992.

ETOPO5: Digital relief of the Surface of the Earth, edited by: N. G. D. C. NOAA, Boulder, Colorado, 1988.

Fernandez, E., Boyd, P., Holligan, P. M., and Harbour, D. S.: Production of organic and inorganic carbon within a large-scale coccolithophore bloom in the Northeast Atlantic Ocean, Mar. Ecol.-Prog. Ser., 97, 271-285, 1993.

Frouin, R., Lingner, D. W., Gautier, C., Baker, K. S., and Smith, R. C.: A simple analytical formula to compute clear sky total and photosynthetically available solar irradiance at the ocean surface, J. Geophys. Res.-Oceans, 94, 9731-9742, 1989.

Garver, S. A., and Siegel, D. A.: Inherent optical property inversion of ocean color spectra and its biogeochemical interpretation. 1. Time series from the Sargasso Sea, J. Geophys. Res.-Oceans, 102, 18607-18625, 1997.

Gregg, W. W. and Carder, K. L.: A simple spectral solar irradiance model for cloudless maritime atmospheres, Limnol. Oceanogr., 35, 1657-1675, 1990.

Gudmundsson, K.: Long-term variation in phytoplankton productivity during spring in Icelandic waters, ICES J. Mar. Sci., 55 , 635-643, 1998.

Häkkinen, S.: A constitutive law for sea ice and some applications, Mathematical Modelling, 9, 81-90, 1987.

Häkkinen, S.: Variability of the simulated meridional heat transport in the North Atlantic for the period 1951-1993, J. Geophys. Res., 104, 10991-11007, 1999.

Häkkinen, S.: Variability in sea surface height: A qualitative measure for the meridional overturning in the North Atlantic, J. Geophys. Res., 106, 13837-13848, 2001.

Häkkinen, S. and Mellor, G. L.: Modeling the seasonal variability of a coupled Arctic ice-ocean system, J. Geophys. Res.-Oceans, 97, 20285-20304, 1992. 
Häkkinen, S. and Geiger, C. A.: Simulated low frequency modes of circulation in the Arctic Ocean, J. Geophys. Res., 105, 65496564, 2000.

Henson, S. A., Dunne, J. P., and Sarmiento, J. L.: Decadal variability in North Atlantic phytoplankton blooms, J. Geophys. Res.Oceans, 114, CO4013, doi:10.1029/2009JC005139, 2009.

Henson, S. A., Sanders, R., Holeton, C., and Allen, J. T.: Timing of nutrient depletion, diatom dominance and a lower-boundary estimate of export production for Irminger Basin, North Atlantic, Mar. Ecol.-Prog. Ser., 313, 73-84, 2006.

Holligan, P. M., Groom, S. B., and Harbour, D. S.: What controls the distribution of the coccolithophore, Emiliania huxleyi, in the North Sea?, Fish. Oceanogr., 2, 175-183, 1993a.

Holligan, P. M., Fernandez, E., Aiken, J., Balch, W. M., Boyd, P., Burkill, P. H., Finch, M., Groom, S. B., Malin, G., Muller, K., Purdie, D. A., Robinson, C., Trees, C. C., Turner, S. M., and Vanderwal, P.: A biogeochemical study of the coccolithophore, Emiliania huxleyi, in the North Atlantic, Global Biogeochem. Cy., 7, 879-900, 1993b.

Jakobsson, J.: The North Icelandic herring fishery and environmental conditions 1960-1968, in: ICES Symposium, The Biological Basis of Pelagic Fish Stock Management, Aberdeen, Scotland, 102 pp., 3-7 July 1978.

Jerlov, N. G.: Marine Optics, New York, Amsterdam, 231 pp., 1976.

Jolliff, J. K., Kindle, J. C., Shulman, I., Penta, B., Friedrichs, M. A. M., Helber, R., and Arnone, R. A.: Summary diagrams for coupled hydrodynamic-ecosystem model skill as sessment, J. Marine Syst., 76, 64-82, 2009.

Lampitt, R. S.: Evidence for seasonal deposition of detritus to the deep-sea floor and its subsequent resuspension, Deep-Sea Res. Pt. I, 32, 885-897, 1985.

Litchman, E., Clausmeier, C. A., Schoefield, O. M., and Falkowski, P. G.: The role of functional traits and trade-offs in structuring phytoplankton communities: scaling from cellular to ecosystem level, Ecol. Lett., 10, 1170-1181, 2007.

Maritorena, S., Siegel, D. A., and Peterson, A. R.: Optimization of a semianalytical ocean color model for global-scale applications, Appl. Optics, 41, 2705-2714, 2002.

Mauritzen, C., and Häkkinen, S.: Influence of sea ice on the thermohaline circulation in the Arctic-North Atlantic Ocean, Geophys. Res. Lett., 24, 3257-3260, 1997.

McKinley, G. A., Fay, A. R., Takahashi, T., and Metzl, N.: Convergence of atmospheric and North Atlantic carbon dioxide trends on multidecadal timescales, Nat. Geosci., 4, 606-610, 2011.

Mellor, G., Häkkinen, S., Ezer, T., and Patchen, R.: A generalization of a sigma coordinate ocean model and an intercomparison of model vertical grids, in: Ocean Forecasting: Conceptual Basis and Applications, edited by: N. P. and J. D. Woods, 55-72, Springer, New York, 2002.

Mellor, G. L.: An equation of state for numerical models of oceans and estuarines, J. Atmos. Oceanic Technol., 8, 609-611, 1991.

Mellor, G. L. and Yamada, T.: Hierarchy of turbulence closure models for planetary boundary-layers, J. Atmos. Sci., 31, 1791-1806, 1974.

Mellor, G. L. and Yamada, T.: Development of a turbulence closure model for geophysical fluid problems, Rev. Geophys. Space Phys., 20, 851-875, 1982.

Mellor, G. L., Hakkinen, S., Ezer, T., and Pazan, R.: A generalization of a sigma coordinate ocean model and an intercompari- son of model vertical grids, in: "Ocean Forecasting: Theory and Practice”, edited by: Pinardi, N. and Woods, J. D., SpringerVerlag, 55-72. Pub., 2002.

Metzl, N., Corbière, A., Reverdin, G., Lenton, A., Takahashi, T., Olsen, A., Johannessen, T., Pierrot, D., Wanninkhof, R., Olafsdottir, S. R., Olafsson, J., and Ramonet, M.: Recent acceleration of the sea surface $f \mathrm{CO}_{2}$ growth rate in the North Atlantic subpolar gyre (1993-2008) revealed by winter observations, Global Biogeochem. Cy., 24, GB4004, doi:10.1029/2009GB003658, 2010.

Morel, A.: Optical modeling of the upper ocean in relation to its biogenous matter content (case-i waters), J. Geophys. Res.Oceans, 93, 10749-10768, 1988.

Nanninga, H. J. and Tyrrell, T.: Importance of light for the formation of algal blooms by Emiliania huxleyi, Mar. Ecol.-Progr. Ser., 136, 195-203, 1996.

Neumann, G. and Pierson, W. J.: Principles of Physical Oceanography, 545 pp., Prentice-Hall, Inc., Englewood Cliffs, NJ, 1966.

Nielsdóttir, M. C., Moore, C. M., Sanders, R., Hinz, D. J., and Achterberg, E. P.: Iron limitation of the postbloom phytoplankton communities in the Iceland Basin, Global Biogeochem. Cy., 23, GB3001, doi:10.1029/2008GB003410, 2009.

Olsen, A., Brown, K. R., Chierici, M., Johannessen, T., and Neill, C.: Sea-surface $\mathrm{CO}_{2}$ fugacity in the subpolar North Atlantic, Biogeosciences, 5, 535-547, doi:10.5194/bg-5-535-2008, 2008.

Poulain, P. M., Warn-Varnas, A., and Niiler, P. P.: Near-surface circulation of the Nordic seas as measured by Lagrangian drifters, J. Geophys. Res.-Oceans, 101, 18237-18258, 1996.

Raitsos, D. E., Lavender, S. J., Pradhan, Y., Tyrrell, T., Reid, P. C., and Edwards, M.: Coccolithophore bloom size variation in response to the regional environment of the subarctic North Atlantic, Limnol. Oceanogr., 51, 2122-2130, 2006.

Rasmusson, E. M. and Mo, K. C.: Large-scale atmospheric moisture cycling as evaluated from NMC global analysis and forecast products, J. Climate, 9, 3276-3297, 1996.

Reynolds, R. W. and Smith, T. M.: A high-resolution global sea-surface temperature climatology, J. Climate, 8, 1571-1583, 1995.

Sambrotto, R. N., Martin, J. H., Broenkow, W. W., Carlson, C., and Fitzwater, S. E.: Nitrate utilization in surface waters of the Iceland Basin during spring and summer of 1989 - The Joint Global Flux Study North-Atlantic Bloom Experiment, Deep-Sea Res. Pt. II, 40 441-457, 1993.

Semtner, A. J.: Model for thermodynamic growth of sea ice in numerical investigations of climate J. Phys. Oceanogr., 6, 379-389, 1976.

Sieracki, M. E., Verity, P. G., and Stoecker, D. K.: Plankton community response to sequential silicate and nitrate depletion during the 1989 North Atlantic spring bloom - The Joint Global Flux Study North-Atlantic Bloom Experiment, Deep-Sea Res. Pt. II, 40, 213-225, 1993.

Signorini, S. R. and McClain, C. R.: Further Studies on Oceanic Biogeochemistry and Carbon Cycling, Technical Memorandum NASA/TM-2003-212245, NASA/TM-2003-212245, NASA Goddard Space Flight Center, Greenbelt, 212251 pp., 2003.

Signorini, S. R., McClain, C. R., and Christian, J. R.: Modeling biogeochemical-physical interactions and carbon flux in the Sargasso Sea (Bermuda Atlantic Time-series Study site), NASA 
Goddard Space Flight Center, Greenbelt, MD, 37, 2001a.

Signorini, S. R., McClain, C. R., Christian, J. R., and Wong, C. S.: Seasonal and interannual variability of phytoplankton, nutrients, $\mathrm{TCO} 2, p \mathrm{CO}_{2}$, and $\mathrm{O}_{2}$ in the Eastern Subarctic Pacific, J. Geophys. Res., 106, 31197-31215, 2001 b.

Sommer, U.: The impact of light-intensity and daylength on silicate and nitrate competition among marine phytoplankton, Limnol. Oceanogr., 39, 1680-1688, 1994.

Steele, M., Morley, R., and Ermold, W.: PHC: A global ocean hydrography with a high-quality Arctic Ocean, J. Climate, 14, 2079-2087, 2001.

Suykens, K., Delille, B., Chou, L., De Bodt, C., Harlay, J., and Borges, A. V.: Dissolved inorganic carbon dynamics and air-sea carbon dioxide fluxes during coccolithophore blooms in the northwest European continental margin (northern Bay of Biscay), Global Biogeochem. Cy., 24, GB3022, doi:10.1029/2009GB003730, 2010.

Sverdrup, H. U.: On conditions for the vernal blooming of phytoplankton, J. Cons. Int. Explor. Mer, 18, 287-295, 1953.

Sweeney, C., Takahashi, T., Olafsson, J., Goddard, J. G., Chipman, D. W., and Sutherland, S. C., Seasonal Variation of $\mathrm{CO}_{2}$ and $\mathrm{Nu}-$ trients in the high-latitude surface oceans - a comparative study, Global Biogeochem. Cy., 7, 843-878, 1993.

Takahashi, T., Sutherland, S. C., Sweeney, C., Poisson, A., Metzl, N., Tilbrook, B., Bates, N., Wanninkhof, R., Feely, R. A., Sabine, C., Olafsson, J., and Nojiri, Y.: Global sea-air $\mathrm{CO}_{2}$ flux based on climatological surface ocean $p \mathrm{CO}(2)$, and seasonal biological and temperature effects, Deep-Sea Res. Pt. II, 49, 1601-1622, 2002.

Takahashi, T., Sutherland, S. C., Wanninkhof, R., Sweeney, C., Feely, R. A., Chipman, D. W., Hales, B., Friederich, G., Chavez, F., Sabine, C., Watson, A., Bakker, D. C. E. , Schuster, U., Metzl, N., Yoshikawa-Inoue, H. , Ishii, M., Midorikawa, T., Nojiri, Y., Kortzinger, A., Steinhoff, T., Hoppema, M., Olafsson, J., Arnarson, T. S., Tilbrook, B., Johannessen, T., Olsen, A., Bellerby, R., Wong, C. S., Delille, B., Bates, N. R., and de Baar, H. J. W.: Climatological mean and decadal change in surface ocean $p \mathrm{CO}_{2}$, and net sea-air $\mathrm{CO}_{2}$ flux over the global oceans, Deep-Sea Res. Pt. II, 56, 554-577, 2009.
Thomas, H., Prowe, A. E. F., Lima, I. D., Doney, S. C., Wanninkhof, R., Greatbatch, R. J., Schuster, U., and Corbiere, A.: Changes in the North Atlantic Oscillation influence $\mathrm{CO}_{2}$ uptake in the North Atlantic over the past 2 decades, Global Biogeochem. Cy., 22, GB4027, doi:10.1029/2007GB003167, 2008.

Tyrrell, T. and Taylor, A. H.: A modelling study of Emiliania huxleyi in the NE Atlantic, J. Mar. Syst. 9, 83-112, 1996.

Vage, K., Pickart, R. S., Thierry, V., Reverdin, G., Lee, C. M., Petrie, B., Agnew, T. A., Wong, A., and Ribergaard, M. H.: Surprising return of deep convection to the subpolar North Atlantic Ocean in winter 2007-2008, Nat. Geosci., 2, 67-72, 2009.

Ullman, D. J., McKinley, G. A., Bennington, V., and Dutkiewicz, S.: Trends in the North Atlantic carbon sink: 1992-2006, Global Biogeochem. Cy., 23, GB4011, doi:10.1029/2008GB003383, 2009.

Wanninkhof, R.: Relationship between wind-speed and gasexchange over the ocean, J. Geophys. Res.-Oceans, 97, 73737382, 1992.

Weeks, A., Conte, M. H., Harris, R. P., Bedo, A., Bellan, I., Burkill, P. H., Edwards, E. S., Harbour, D. S., Kennedy, H., Llewellyn, C., Mantoura, R. F. C., Morales, C. E., Pomroy, A. J., and Turley, C. M.: The physical and chemical environment and changes in community structure associated with bloom evolution - the joint global flux study North Atlantic bloom experiment, Deep-Sea Res. Pt. II, 40, 347-368, 1993.

Weiss, R. F.: The solubility of nitrogen, oxygen, and argon in water and seawater, Deep-Sea Res. Pt. I, 17, 721-735, 1970.

Weiss, R. F.: Carbon dioxide in water and seawater: the solubility of a non-ideal gas, Mar. Chem., 2, 203-215, 1974.

Yaglom, A. M. and Kader, B. A.: Heat and mass-transfer between a rough wall and turbulent fluid-flow at high Reynolds and Peclet numbers, J. Fluid Mech., 62, 601-623, 11 February 1974.

Zhai, L., Gudmundsson, K., Miller, P., Peng, W., Guðfinnsson, H., Debes, H., Hátún, H., White III, G. N., Walls, R. H., Sathyendranath, S., and Platt, T.: Phytoplankton phenology and production around Iceland and Faroes, Cont. Shelf. Res., 37, 15-25, doi:10.1016/j.csr.2012.01.013, 2012. 